Research Article

\title{
Experimental Assessment on the Hysteretic Behavior of a Full-Scale Traditional Chinese Timber Structure Using a Synchronous Loading Technique
}

\author{
XiWang Shi $\mathbb{D}^{1},{ }^{1}$ Y. Frank Chen $\mathbb{D}^{2,3}{ }^{2,3}$ JinYong Chen, ${ }^{1}$ QingShan Yang, ${ }^{2,4}$ and TieYing Li $\mathbb{D}^{1}$ \\ ${ }^{1}$ College of Architecture and Civil Engineering, Taiyuan University of Technology, Taiyuan 030024, China \\ ${ }^{2}$ School of Civil Engineering, Chongqing University, Chongqing 400044, China \\ ${ }^{3}$ Department of Civil Engineering, The Pennsylvania State University, Middletown, PA 17057, USA \\ ${ }^{4}$ Beijing's Key Laboratory of Structural Wind Engineering and Urban Wind Environment, Beijing 100044, China \\ Correspondence should be addressed to Y. Frank Chen; yxc2@psu.edu and TieYing Li; 1ty680412@163.com
}

Received 16 November 2017; Accepted 18 January 2018; Published 15 March 2018

Academic Editor: Jun Liu

Copyright (c) 2018 XiWang Shi et al. This is an open access article distributed under the Creative Commons Attribution License, which permits unrestricted use, distribution, and reproduction in any medium, provided the original work is properly cited.

In traditional Chinese timber structures, few tie beams were used between columns, and the column base was placed directly on a stone base. In order to study the hysteretic behavior of such structures, a full-scale model was established. The model size was determined according to the requirements of an eighth grade material system specified in the architectural treatise Ying-zao-fa-shi written during the Song Dynasty. In light of the vertical lift and drop of the test model during horizontal reciprocating motions, the horizontal low-cycle reciprocating loading experiments were conducted using a synchronous loading technique. By analyzing the load-displacement hysteresis curves, envelope curves, deformation capacity, energy dissipation, and change in stiffness under different vertical loads, it is found that the timber frame exhibits obvious signs of self-restoring and favorable plastic deformation capacity. As the horizontal displacement increases, the equivalent viscous damping coefficient generally declines first and then increases. At the same time, the stiffness degrades rapidly first and then decreases slowly. Increasing vertical loading will improve the deformation, energy-dissipation capacity, and stiffness of the timber frame.

\section{Introduction}

A large number of traditional timber structures have been damaged during earthquakes. For instance, during the ChiChi earthquake in Taiwan, a total of 742 traditional timber structures were damaged in the areas seriously affected by the earthquake [1]. During the Wenchuan earthquake in Sichuan Province, China, nearly 10,000 traditional timber structures in 419 sites protecting cultural relics were damaged to various degrees [2]. Therefore, there is an urgent need to protect and repair the traditional timber structures to preserve their significance and heritage value. In particular, the seismic behavior of these structures needs to be studied thoroughly.

A traditional timber structure in East Asia consists of a roof layer, bracket set layer, column framework, and platform base. A good example is the Yingxian Wooden Pagoda in
Shanxi Province, China (Figures 1(a) and 1(b)). The seismic behavior of this complex structure has drawn much attention from scholars. However, certain seismic issues including the roof space system with large self-weight and stiffness, the energy dissipation in the bracket sets due to shear friction (Figure 1(c)), the semirigid connection in mortise and tenon joints [3], and the column base resting directly on a stone base [4] (Figure 1(d)) have not been fully studied. Researchers have investigated the hysteretic behavior of bracket sets and mortise-tenon joints by performing horizontal and low-cycle reciprocating loading experiments.

A bracket set is a unique construction used in traditional Chinese timber structures. The proportion of the rotational and slip motion (the main seismic behavior of bracket sets) in each block and corbel has been analyzed using reducedscale $(1 / 3.25$ and $2 / 3)$ and full-scale models to obtain the primary deformation of each component [5-8]. The rotation 


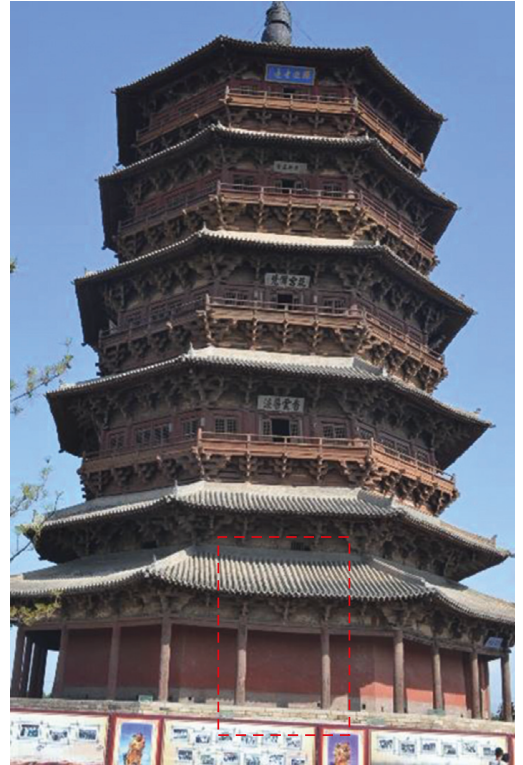

(a)

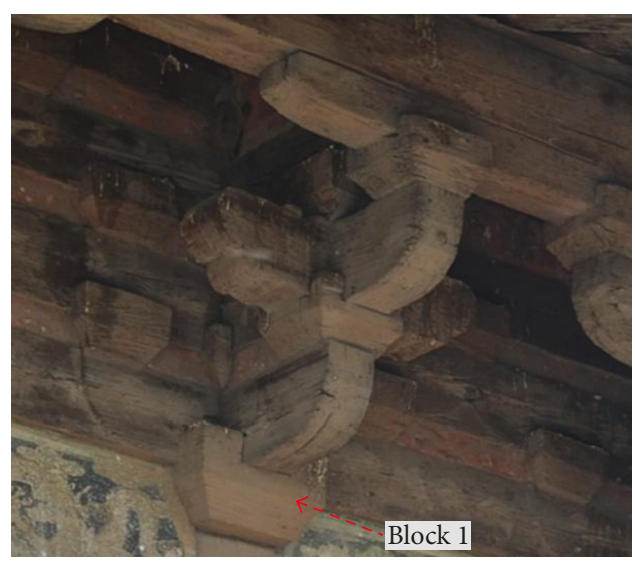

(c)

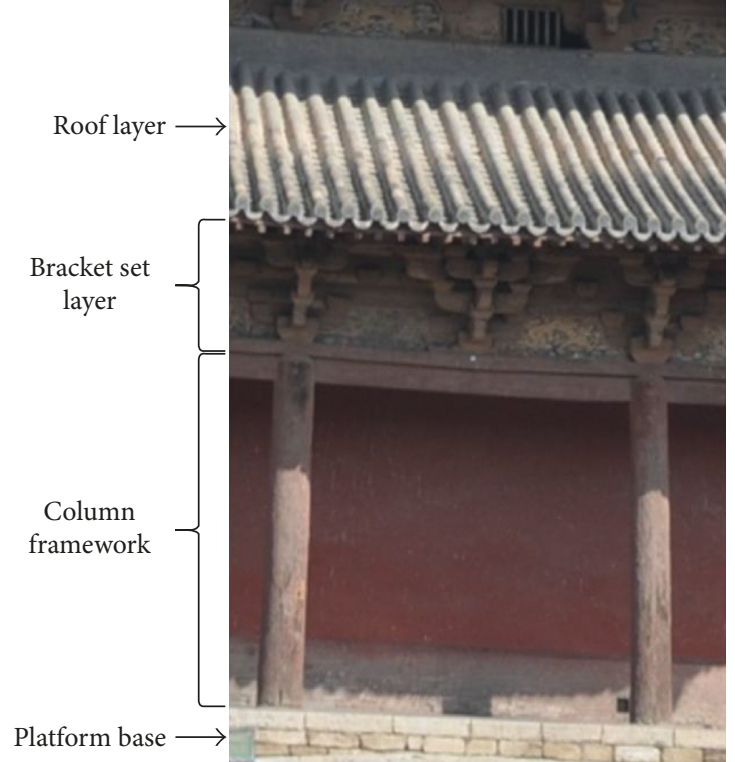

(b)

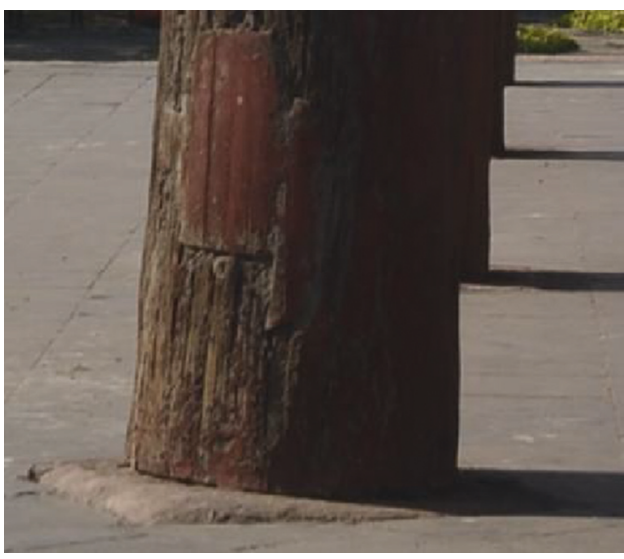

(d)

Figure 1: Traditional timber structures. (a) Yingxian Wooden Pagoda; (b) traditional timber structure; (c) bracket set; (d) the column base resting directly on a stone base.

of block 1 (the lowest layer in the bracket set, as shown in Figure 1(c)) has a great influence, especially with respect to the initial stiffness. The initial stiffness of a bracket set can be determined from the elastic deformation of the wood perpendicular to the grain of the bottom of block 1 . The restoring forces and skeleton curves of simplified models can be established according to the hysteresis curves in which the force-displacement relationship is highly dependent on the rotational spring stiffness and vertical load. It appears that the yield moment is improved when a heavier vertical load is imposed on the structure.

The hysteretic behavior of mortise-tenon joints of beam columns of different types also exhibits some differences. The restoring forces and skeleton curves for simplified models of different mortise-tenon joints have been established according to tests on reduced-scale models of the column framework (ratios of 1/3.25 and 1/2) [9, 10]. Among them, dovetailed mortise and tenon joints possess the largest horizontal lateral stiffness but degrade more rapidly, and their strength is generally lower than that of penetrated mortise-tenon joints. The full nature of hysteresis curves indicates a favorable energy-dissipation capacity.

In addition, gaps induced from fabrication, or due to installation error, or joint looseness resulting from cyclic loading also exerts a certain influence on the hysteretic behavior of mortise-tenon joints [11, 12]. In general, the initial slip increases proportionally to the increase in the gap size. The existence of gaps in the contacting area lowers the moment resistance and strain energy.

Horizontal low-cycle and reciprocating loading tests of mortise-tenon joints can be performed using a column framework model. However, these tests assume a hinge joint between the column and stone base which is contrary to the column base resting directly on a stone base in the traditional timber structures and ignore the rotation that may occur around the perimeter of the column. Moreover, an 


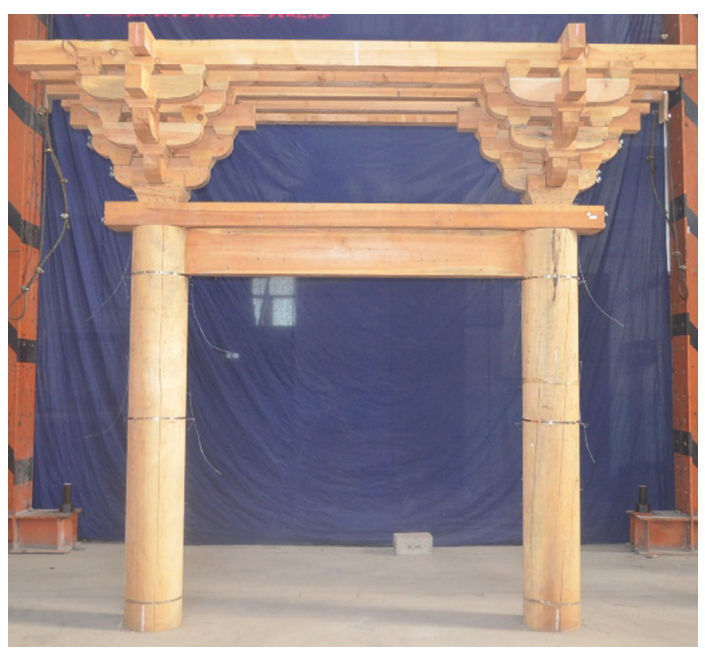

(a)

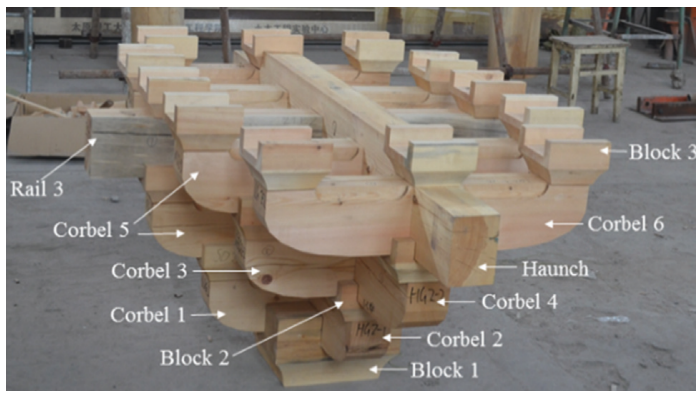

(c)

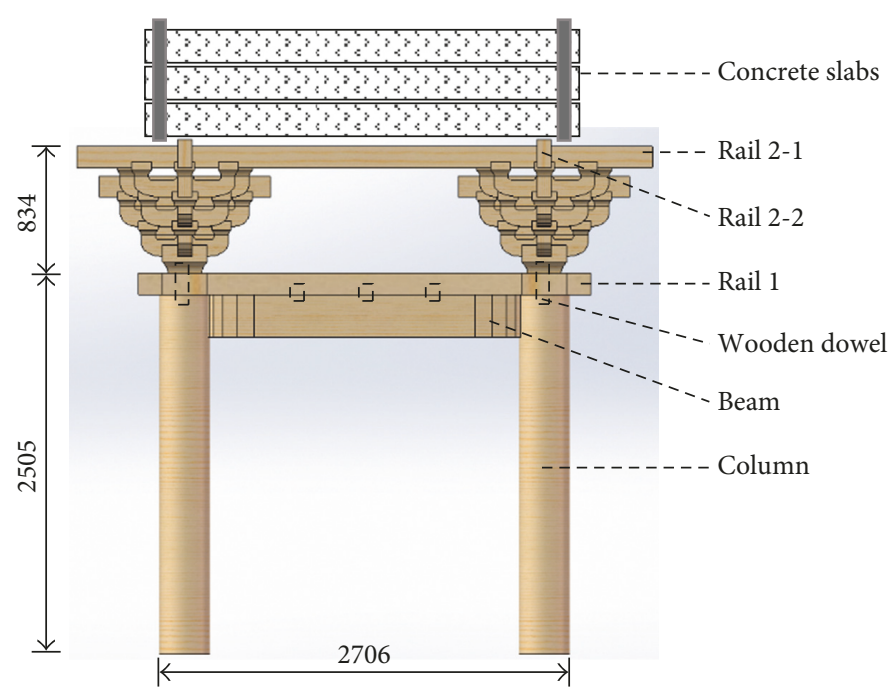

(b)

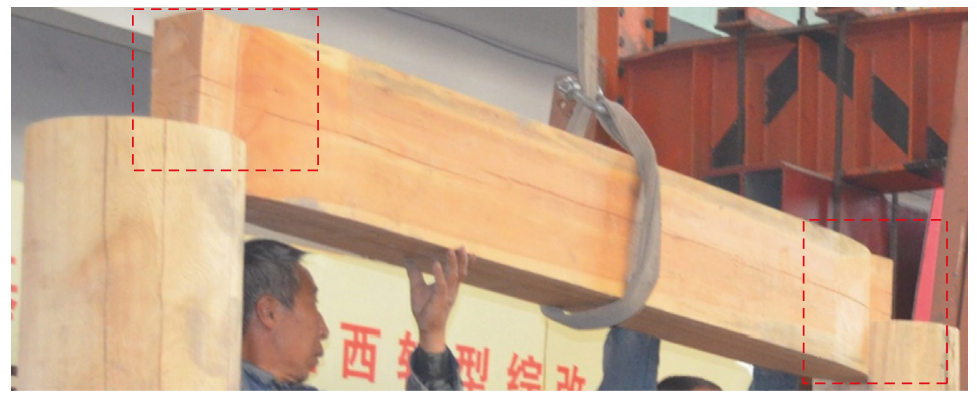

(d)

FIGURE 2: Test model with dimensions in mm. (a) Full-scale model; (b) elevation of the full-scale model; (c) dissembled view of the bracket set; (d) dovetailed mortise and tenon joint.

actuator or jack has been frequently used to impose vertical or horizontal forces, which limit the vertical lift and drop of a column framework during reciprocating horizontal motions. Simplifying the joints and restricting the loading method undoubtedly change the deformation of the timber structure and the resulting internal forces. This is even more evident in full-scale models.

It must be noted that, in numerous tests investigating the hysteretic behavior of traditional timber structures, reducedscale models exhibit size effects compared to full-scale models. To this date, limited study on size effects has been carried out $[13,14]$. Tsuwa et al. [5] analyzed a bracket set using three different scale ratios $(2 / 3,1 / 1$, and $3 / 2)$. The structures' stiffness changed at a rate approximately proportional to the square of the scale ratio of the specimens. Compared to other specimens, the rigidity of the $2 / 3$ specimen was higher, and its normalized horizontal force was about three times. However, quantitative relations for other parameters, such as the proportions of sliding and rotation friction of each component of the bracket sets relative to scale, are not known. In addition, definite quantitative relationships describing the influence of various structural components (e.g., bracket sets, mortise-tenon joints, and column framework) on the whole timber structure are also unknown. Hence, it is better to use a full-scale model to represent the traditional timber structure to capture its true hysteretic behavior.

Full-scale tests on traditional timber structures using low-cycle reciprocating loads are relatively limited. Suzuki et al. [15-17] conducted a full-scale test on a Japanese traditional timber structure using the column base resting directly on a stone base to establish the restoring force acting on the model structure. It was found that the restoring force due to column rocking contributed most to the total restoring force when the frame deformation was small and that the bending moment from tie beams became dominant with the increasing deformation. The axial forces in the columns, dependent mainly on the roof weight, had little influence on the bending moment resistance of tie beams. However, a heavier roof would cause a larger restoring force due to its effect on column rocking.

Traditional Chinese timber structures are different from those built in Japan. In particular, traditional Japanese timber structures generally have tie beams between columns [18]. Park et al. [19] carried out horizontal low-cycle reciprocating loading tests on column frameworks with and without tie beams between columns. In the elastic region, the tie beams had no significant effect on the characteristic structural coefficients (e.g., initial stiffness of the framework) and energy dissipation. This is due to the slight gap existing 
TABLE 1: Sizes of the main elements (all dimensions in $\mathrm{mm}$ ).

\begin{tabular}{|c|c|c|c|c|}
\hline Member & Photo & $\begin{array}{l}\text { Cross } \\
\text { section }\end{array}$ & Length & Number \\
\hline Column & As shown in Figure 2 & 334 & 2366 & 2 \\
\hline Beam & As shown in Figure 2 & $278 \times 185$ & 2224 & 1 \\
\hline Rail 1 & As shown in Figure 2 & $297 \times 139$ & 2987 & 1 \\
\hline Rail 2-1 & As shown in Figure 2 & $139 \times 93$ & 3800 & 5 \\
\hline Rail 2-2 & As shown in Figure 2 & $185 \times 93$ & 1576 & 2 \\
\hline Block 1 & & $185 \times 297$ & 297 & 2 \\
\hline Block 2 & & $147 \times 93$ & 166 & 8 \\
\hline Block 3 & & $147 \times 93$ & 130 & 40 \\
\hline Corbel 1 & & $139 \times 93$ & 576 & 2 \\
\hline Corbel 2 & & $195 \times 93$ & 666 & 2 \\
\hline Corbel 3 & & $139 \times 93$ & 576 & 4 \\
\hline Corbel 4 & & $195 \times 93$ & 1222 & 2 \\
\hline Corbel 5 & & $139 \times 93$ & 852 & 6 \\
\hline Corbel 6 & & $139 \times 93$ & 668 & 4 \\
\hline Haunch & & $195 \times 93$ & 1576 & 2 \\
\hline Rail 3 & & $139 \times 93$ & 1130 & 2 \\
\hline
\end{tabular}

at the joint between the post and the tie beam. However, certain coefficients (including the ductility factor) and energy dissipation in the column framework containing tie beams were improved in the plastic region. It seems clear that different facets of the construction method result in different structural characteristics.

In order to investigate the hysteretic behavior of traditional Chinese timber structures, the horizontal low-cycle reciprocating load test was carried out on the full-scale model in which the column base was placed directly on the stone base by using a developed synchronous loading scheme. The properties including deformation, energy dissipation, and stiffness variations of the full-scale model under different vertical loads were analyzed. The concluding results are useful in terms of the protection and preservation of existing traditional Chinese timber structures.

\section{Design and Preparation of the Full-Scale Model}

A single span of a traditional Chinese timber structure was selected in this study. According to the size requirements of an eighth grade system specified in the Ying-zao-fa-shi (a construction method of pre-1386) from the Song Dynasty [20], a full-scale model with a single span was prepared (Figure 2(a)). Detailed sizes for the components are shown in Table 1.

The test model was designed to allow the vertical lift and drop under horizontal reciprocating motions. As the roof of the traditional structure has a significant weight and
TABle 2: Material properties of the full-scale test model.

\begin{tabular}{lccc}
\hline Mechanical properties & $\begin{array}{c}\text { Forced } \\
\text { direction }\end{array}$ & $\begin{array}{c}\text { Test } \\
\text { result } \\
(\mathrm{MPa})\end{array}$ & $\begin{array}{c}\text { Coefficient } \\
\text { of variation }\end{array}$ \\
\hline Bending elastic modulus & $\begin{array}{c}\text { Radial } \\
\text { Tangential }\end{array}$ & $\begin{array}{c}7607 \\
7809\end{array}$ & 0.118 \\
Bending strength & $\begin{array}{c}\text { Radial } \\
\text { Tangential }\end{array}$ & $\begin{array}{c}74.93 \\
65.73\end{array}$ & 0.133 \\
MOE in compression & Radial & 377 & 0.113 \\
perpendicular to grain & Tangential & 183 & 0.143 \\
Compression strength & Radial & 4.55 & 0.193 \\
perpendicular to grain & Tangential & 5.41 & 0.128 \\
$\begin{array}{l}\text { Local compression strength } \\
\text { perpendicular to grain }\end{array}$ & $\begin{array}{c}\text { Radial } \\
\text { Tangential }\end{array}$ & 5.94 & 0.086 \\
$\begin{array}{l}\text { MOE in compression } \\
\text { Compression strength }\end{array}$ & - & 3031 & 0.202 \\
$\begin{array}{l}\text { parallel to grain } \\
\text { Tensile strength parallel to } \\
\text { grain }\end{array}$ & - & 41.19 & 0.112 \\
\hline
\end{tabular}

horizontal translational stiffness, the structure can be approximately treated as a rigid system $[21,22]$. Therefore, the roof layer was replaced with a concrete slab [15-17] (Figure 2 (b)). Bracket sets consisting of the lattice of square blocks and bow-shaped corbels were laid on the top of the columns (Figure 2(c)). The bracket set layer was constructed by connecting bracket sets using rails 2 , and the load from the roof layer was thus transferred to the column framework. Wooden dowels were used to connect columns and rail 1 (the structure on the architrave used to connect columns) as well as rail 1 and the beam. The columns were connected with the beam using dovetailed mortise and tenon joints (Figure 2(d)), and the upper load was transferred to the platform base through the column bases. For safety reasons, a concrete ground with a friction coefficient approximate of stone bases was used to form the platform base, and the column bases were laid directly on the concrete ground.

The full-scale test model was constructed using Pinus sylvestris imported from Russia. Material quality tests were also conducted on the same batch of Pinus sylvestris according to the required standards [23]. The air-dried density was found to be $0.435 \mathrm{~g} / \mathrm{cm}^{3}$ when the moisture content of the Pinus sylvestris was $9.39 \%$, and the fully dried density was $0.412 \mathrm{~g} / \mathrm{cm}^{3}$. Specific mechanical properties are listed in Table 2.

\section{Loading and Measurement Scheme}

3.1. Loading Equipment. During the horizontal low-cycle and reciprocating loading tests, the full-scale model was rotated around the perimeter of the column base, and the arc motion could thus induce vertical lift and drop. The concrete slabs and horizontal synchronous loading device were applied to simulate, respectively, the vertical and horizontal loads (Figure 3(a)).

The horizontal loading device consists of steel columns, bar chains, spherical hinge bearings, cross girders, fixed pulley 


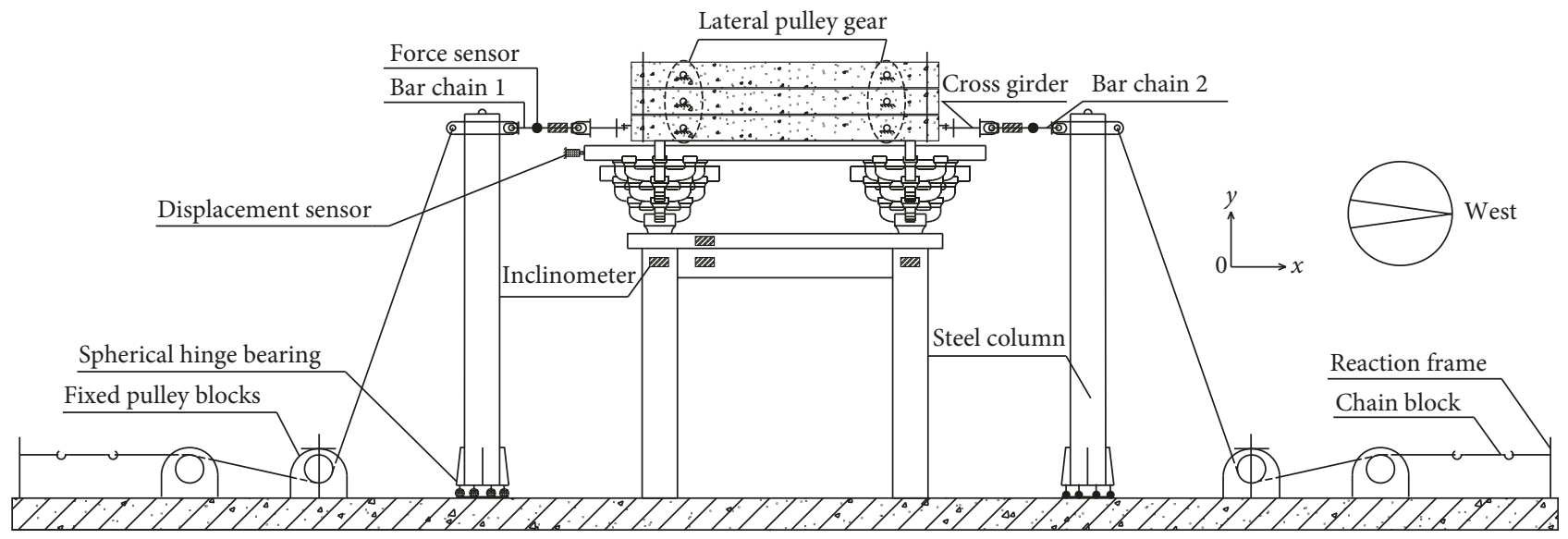

(a)

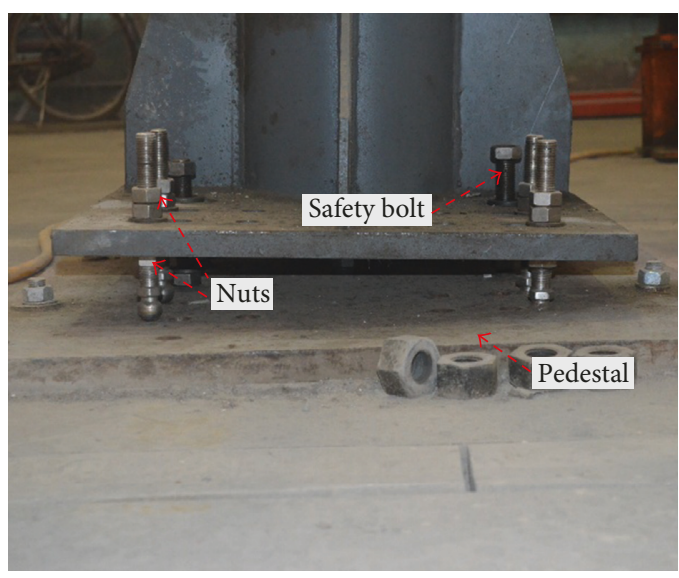

(b)

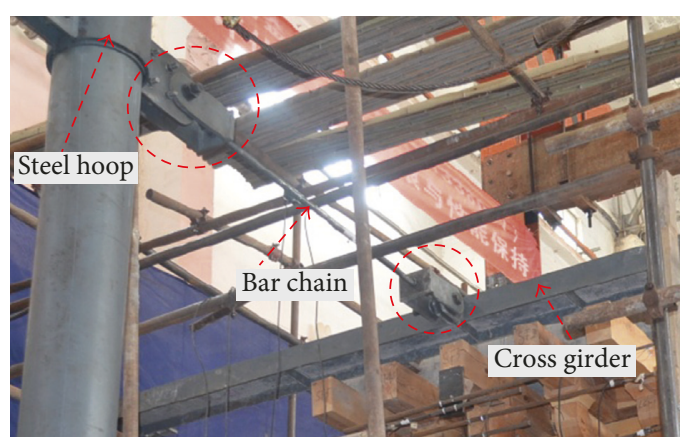

(d)

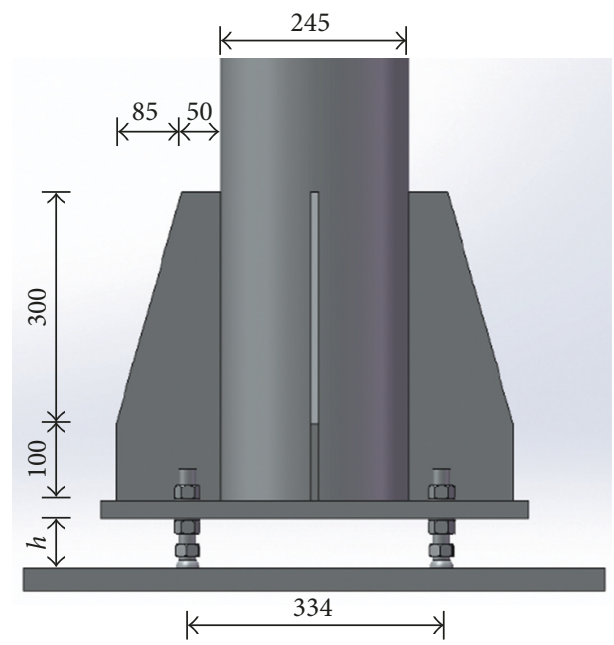

(c)

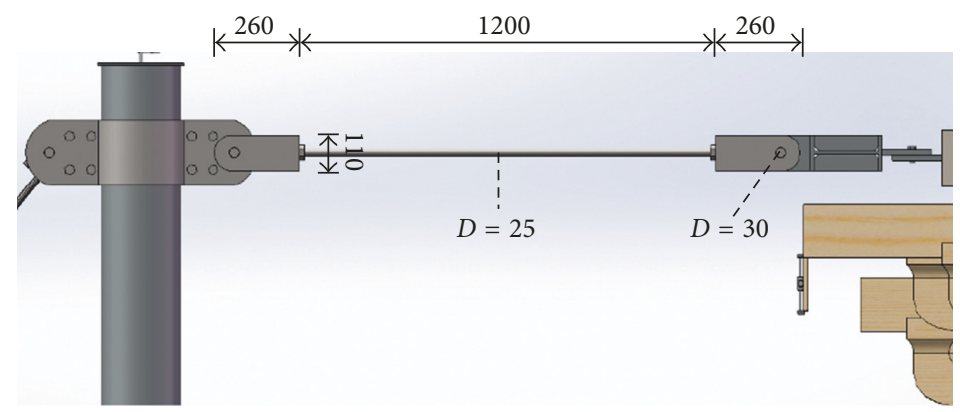

(e)

Figure 3: Continued. 


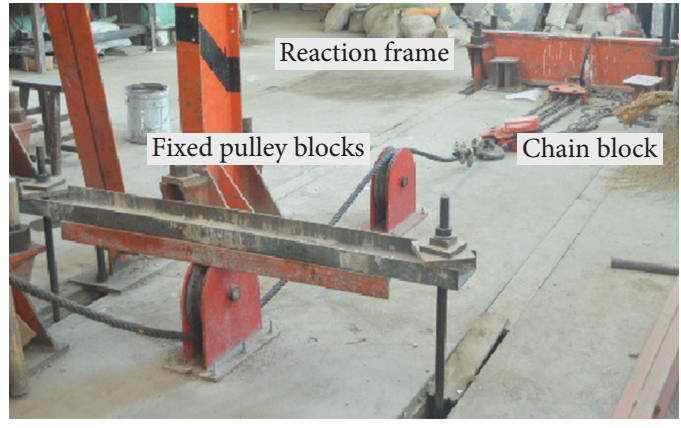

(f)

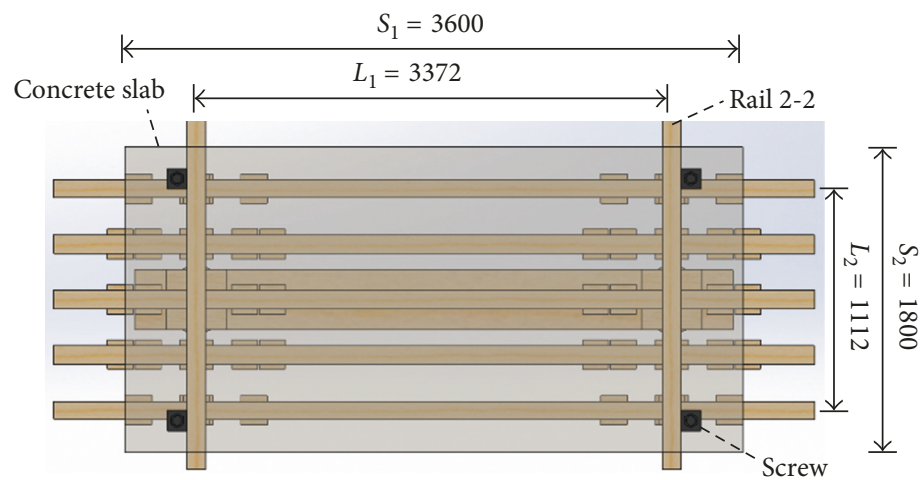

(g)

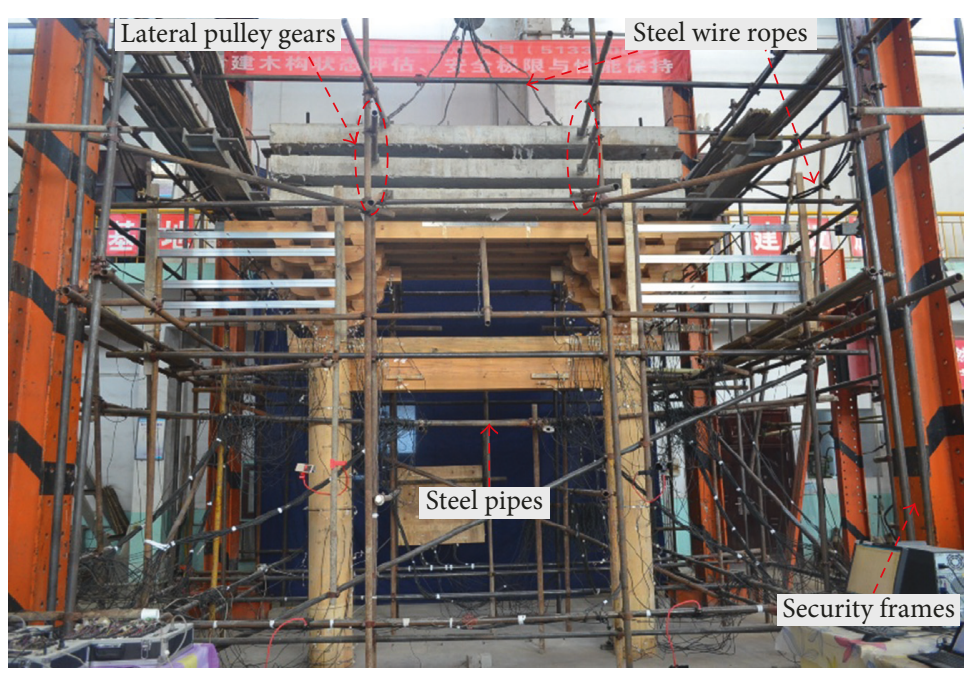

(h)

Figure 3: Loading equipment and safety devices (mm). (a) Overview of the test setup and layout of instrumentations; (b-c) spherical hinge bearings; (d-e) the connection of the bar chains; (f) mechanism of force application; (g) size of the concrete slab; (h) safety devices.

blocks, chain blocks, reaction frames, and steel wire ropes. The chain blocks were fixed on the reaction frames, and the tensile force imposed by them was transferred to the steel columns via the steel wire ropes. The steel columns subsequently imposed the horizontal tensile force onto the cross girders via the bar chains which were fixed within the concrete slab. As a result, a horizontal loading was imposed on the test model.

A few notes concerning the horizontal synchronous loading device are worthy of mentioning, as follows:

(1) Spherical hinge bearings with $20 \mathrm{~mm}$ in diameter and $150 \mathrm{~mm}$ in length were used to connect the pedestals and steel column bases (Figures $3(\mathrm{~b})$ and 3 (c)). By adjusting the height of the bolts, the height $h$ between the pedestal and the steel column base was set to be not less than $50 \mathrm{~mm}$ ( $=60 \mathrm{~mm}$ in this study) so that the steel columns could freely rotate in horizontal reciprocating motions. Moreover, the spacing of the spherical hinge bearings along the loading direction was set to be equal to the diameter of the column of the model $(=334 \mathrm{~mm})$ so that the synchronous rotation of the steel column and model column could be attained (Figures 3(b) and 3(c)).
(2) The bar chains, cross girders, and steel columns were connected through hinge joints to form a four-chain mechanism consisting of the steel columns, bar chains, and test model (Figures 3(d) and 3(e)). By doing so, the force imposed by the bar chains on the test model was guaranteed to be horizontal at all times. When connecting the bar chains and steel columns, it was necessary to ensure that the bar chains were horizontal in the initial state, which could be done by adjusting the height of the steel hoops.

(3) The tensile direction imposed on the steel columns (i.e., on the centers of the cross sections of the test model) by the steel wire ropes was fixed using two fixed pulley blocks (Figure 3(f)). Although pulled manually, the chain blocks showed a low loading rate (about $0.35 \mathrm{~m} / \mathrm{s}$ ), meaning that the loading was approximately uniform. In addition, while one side of the model was in tension during cyclic loading, the steel wire rope on the other side was loosened to satisfy the horizontal displacement of the test model of $300 \mathrm{~mm}$. Apart from their effect on loading, the chain blocks also served the purpose of safety as they 


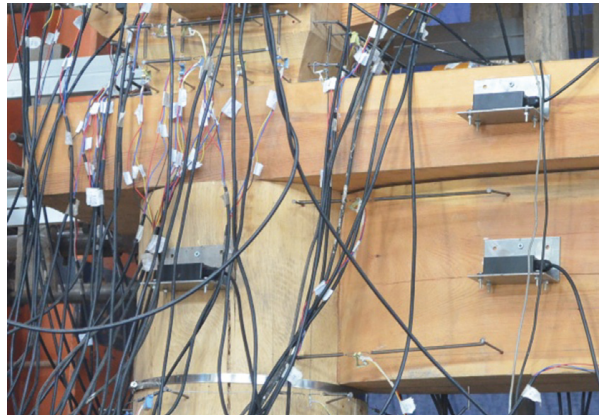

(a)

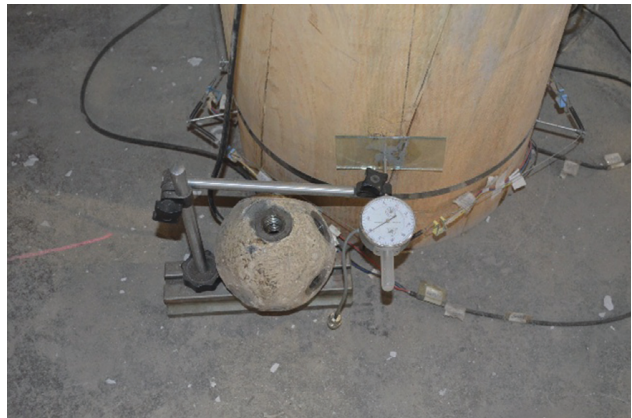

(b)

Figure 4: Measurement schemes. (a) Inclinometers; (b) dial indicator.

provided a protection in case the test model would collapse in the loading direction.

(4) The synchronous loading device could be used to rectify any deviation of the tilt timber structure layer by layer, except for the intended horizontal loading performed during the test.

The vertical loading was increased by adding more concrete slabs. The weight of the roof (based on the size requirements of eighth grade materials) was calculated according to the roof type and the roof load encountered in different working conditions [24]. Based on the analysis of the three-level vertical loads required in the horizontal reciprocating loading tests, three concrete slabs were prepared with each weighing $30 \mathrm{kN}$. As the top face of rail 2-2 was higher than that of rail 2-1, the size of the concrete slabs need not be less than the span between the rails 2 (i.e., $S_{1} \geq L_{1}, S_{2} \geq L_{2}$ ). As a result, the vertical load was directly transferred to the bracket sets underneath. It was thus determined that $S_{1}=3.6 \mathrm{~m}$ and $S_{2}=1.8 \mathrm{~m}$, and that the height was $0.18 \mathrm{~m}$ (Figure $3(\mathrm{~g})$ ).

To ensure that the tests were conducted safely, various safety devices were employed, including security frames, scaffolds, screws (Figure 3(g)), steel wire ropes, cranes, and lateral pulley gears, in addition to the synchronous loading device (Figure $3(\mathrm{~h})$ ). In the roof layer, the concrete slabs were fixed together using screws connected to the security frame and crane using steel wire ropes such that a rope length of $300 \mathrm{~mm}$ was reserved to ensure no tensile force during a test. In order to avoid out-of-plane torsion and even lateral collapse of the test model, 12 lateral pulley gears were placed out of the plane of the concrete slabs. The frictional force between the two substances was so low that it could be considered negligible. To protect the bracket set layer and column framework, it was necessary to reserve a certain horizontal displacement of $300 \mathrm{~mm}$ between the test model and the scaffolds. The steel pipes were also installed out of the plane on both sides of the column framework. In addition, a gap of $20 \mathrm{~mm}$ was reserved between a steel pipe and a column of the model in order to eliminate the friction. After completing a test, it was necessary to tighten the safety bolts of the spherical bearings (Figure 3(b)), remove the concrete slabs, and tighten the chain blocks.

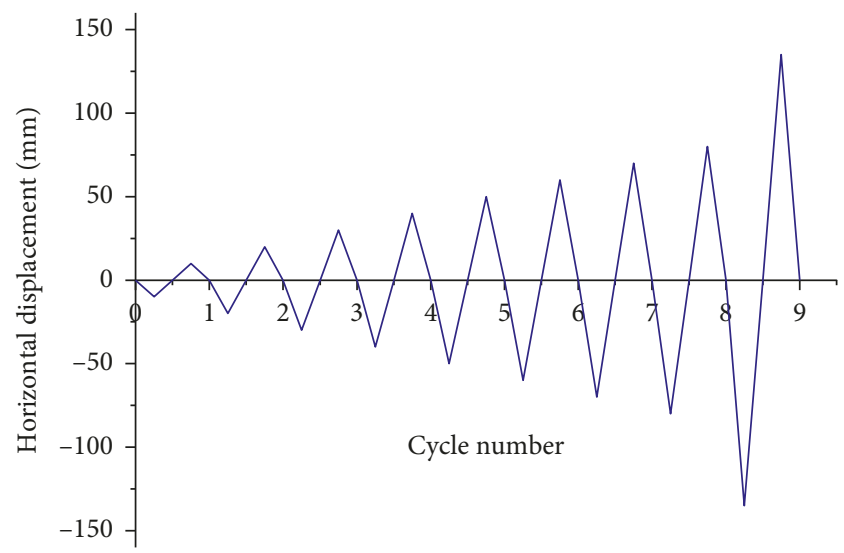

FIGURE 5: Loading system.

3.2. Measurement Schemes. In order to measure the horizontal forces and displacements of the overall structure, two force sensors and one horizontal displacement sensor $[25,26]$ were arranged separately on two bar chains and rail 2-1 (Figure 3(a)). To observe the state of deformation of the components at the mortise-tenon joints and whether the bar chains remain horizontal during tests, six dual-axis digital inclinometers (model SVT626T) were arranged separately on the two columns, beam, rail 1, and two bar chains (Figures 3(a) and 4(a)). Measurements were recorded in real time using a data acquisition instrument. The horizontal tensile forces and displacements are defined as positive if directed towards the west, while a clockwise rotation is defined as the positive inclination. Additionally, two dial indicators were set up out of the plane at the column bottoms in order to determine if any out-of-plane torsion occurred in the test model (Figure 4(b)).

3.3. Loading System. The vertical loads were applied at three different levels: $30 \mathrm{kN}, 60 \mathrm{kN}$, and $90 \mathrm{kN}$, and a variableamplitude displacement controller was employed to generate the horizontal reciprocating loading under each vertical load level. The horizontal displacements used were \pm 10 , $\pm 20, \pm 30, \pm 40, \pm 50, \pm 60, \pm 70, \pm 80$, and \pm Max mm (note: Max $=$ the maximum control displacement corresponding to constantly increasing horizontal displacement and reducing 


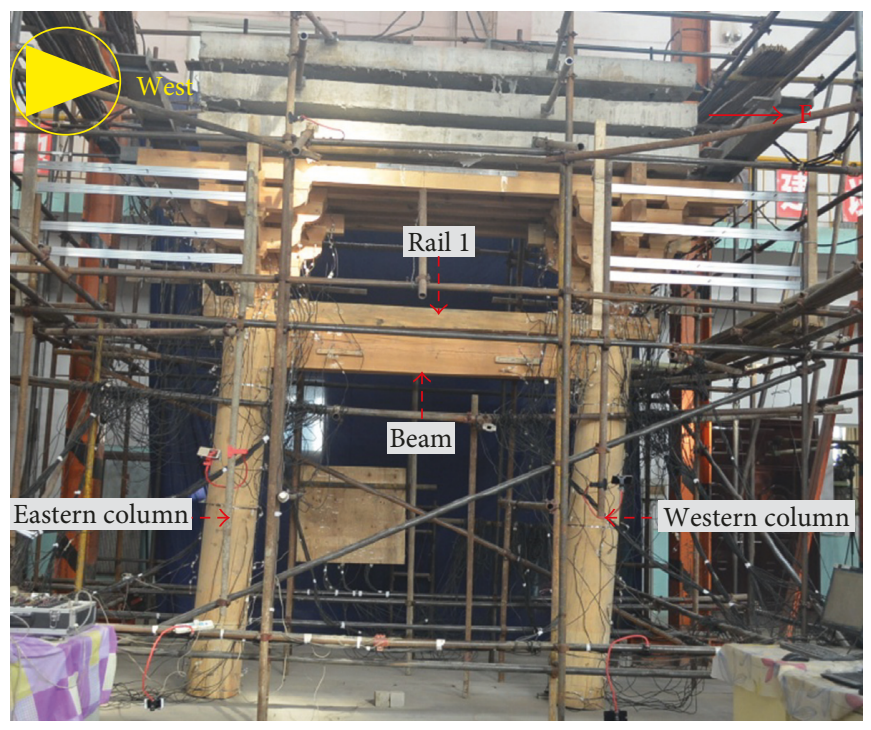

(a)
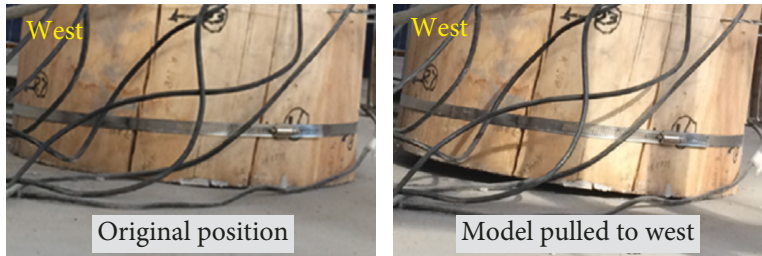

(b)
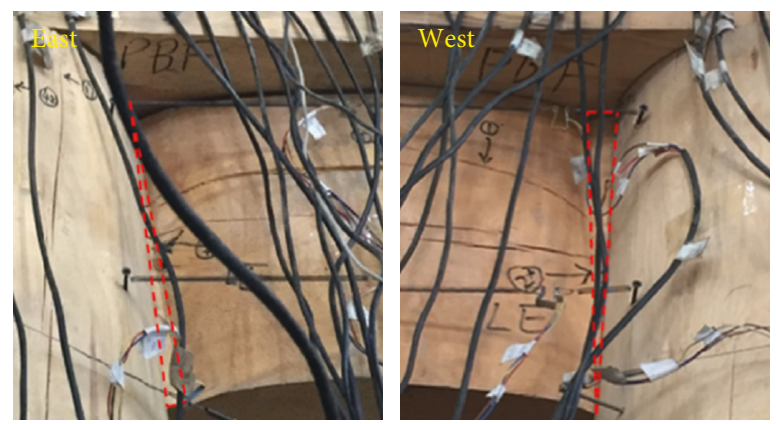

(c)

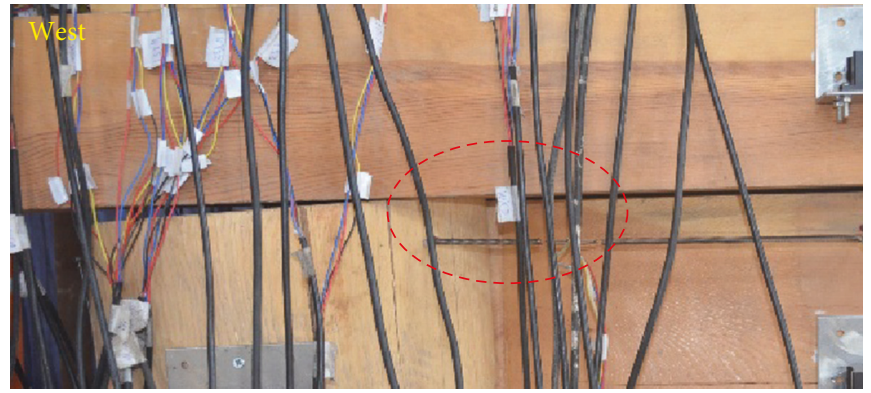

(d)

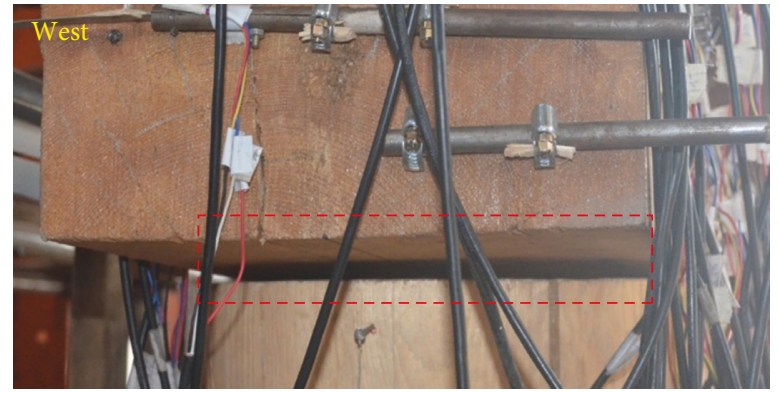

(e)

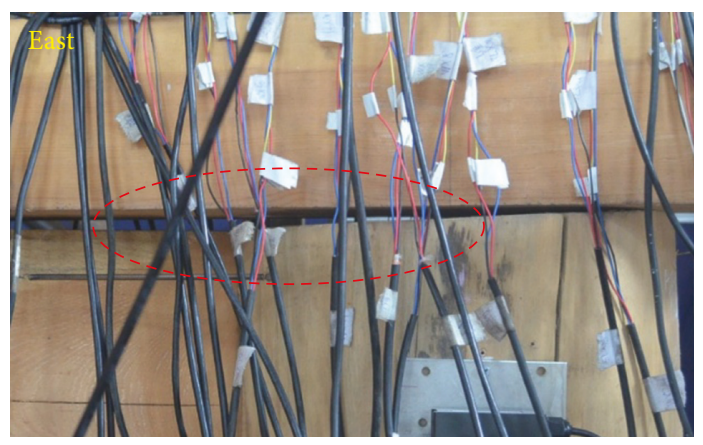

(f)

Figure 6: Continued. 

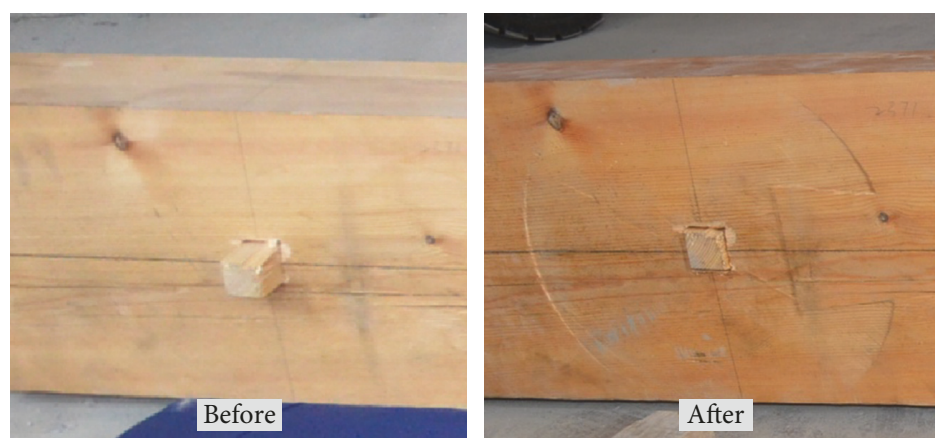

(g)

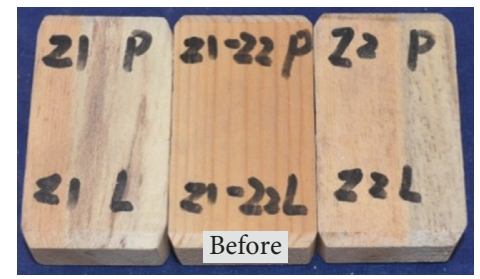

(i)

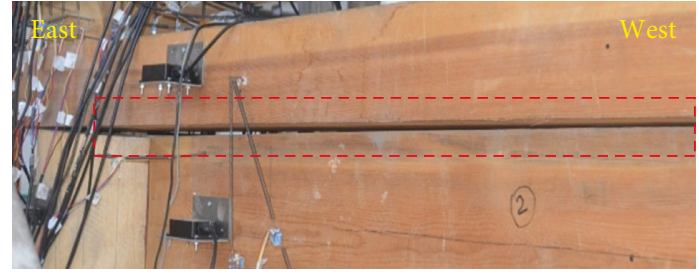

(h)

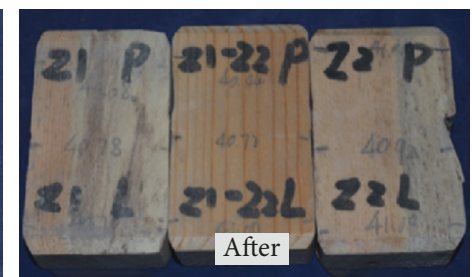

Figure 6: Deformation of the test model.

horizontal force). Each level of controlled displacement was applied for one reciprocating cycle using the loading system shown in Figure 5.

The test model was prepressed for 24 hours after the vertical loading but before the horizontal loading. After the deformation of the model stabilized, the bar chains were installed to remove the effect of vertical compressive deformation on the initially horizontal bar chains. Also, to achieve a "stable deformation" for the test model, the model needs to be loaded to the controlled displacement level and unloaded to a balanced state (i.e., when the strain in bar chains 1 and $2=0$ ) for 5 minutes in each stage.

\section{Descriptions of the Test Process and Phenomena}

Prior to the horizontal reciprocating loading, various initial sizes and defects (e.g., fractures) of each component of the test model were precisely measured and recorded in order to distinguish and compare the deformations occurring during the tests. To avoid compression damage between the components of the test model, the components were assembled on the site and checked to ensure that there were no gaps between the tightly contacting components of the assembled model. Additionally, it was necessary to ascertain whether the various monitoring systems (force, displacement, and inclination sensors) worked normally and whether the initial state of the bar chains was in horizontal position prior to the horizontal loading. Moreover, it was examined whether the interval between the spherical bearings was the same as the column diameter of the model and whether the reserved lengths of the steel wire ropes and spherical bearing bolts were correct.

As shown in Figure 6(a), when the western side of the test model was pulled during the horizontal reciprocating loading, the eastern side of the steel wire rope was reserved for the western horizontal displacement of the test model (set to $300 \mathrm{~mm}$ ) in order to guarantee that the bar chain on the eastern side was not pulled. When the western side of the test model was pulled, the inclination of the western column was found to be larger than that of the eastern column, and this difference in inclination increased as the horizontal displacement increased. Besides, the edges at the bottom and top of the columns appeared to have subjected to compression deformation, and the test model appeared to have vertically lifted and dropped due to the rotation around the perimeter at the column bottom (Figure 6(b)).

The tenons of the mortise-tenon joints were obliquely pulled out from their mortises on both western and eastern sides when the western side of the model was pulled (Figure $6(\mathrm{c}))$. The extent of the pullout was larger in the tenon on the western side than that on the eastern side. The extent of the pullout changed rapidly initially, but the rate of change slowed down as the horizontal displacement increased. The mortises became loose due to the mutual compression with the tenons, indicating that there was a large lateral compression of the mortises on the tenons.

The western column and beam of the column framework were tightly compressed with rail 1 (Figure 6(d)) when the western side of the model was pulled so that the western side of rail 1 became tilted relative to the column top (Figure 6(e)). Meanwhile, large gaps appeared between the eastern column, beam, and rail 1 (Figure 6(f)), and compression deformation occurred between rail 1 and the eastern and western columns (Figure $6(\mathrm{~g})$ ). It can be speculated that the wooden dowels used to connect the columns and rail 1 experienced large bending moments and that rail 1 was subsequently subjected to bending deformation (as the wooden dowels experience different bending moments on the two sides of rail 1). Additionally, the beam underwent 


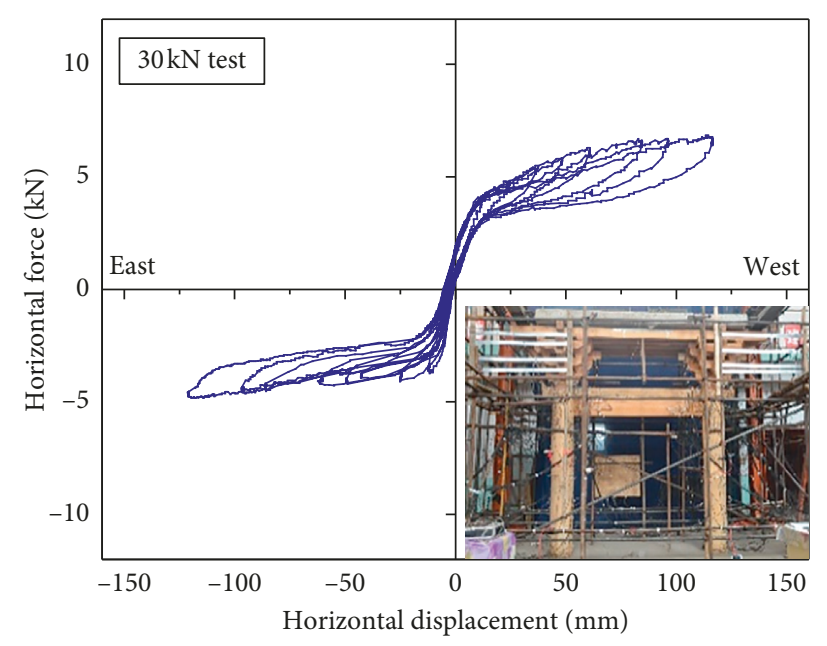

(a)

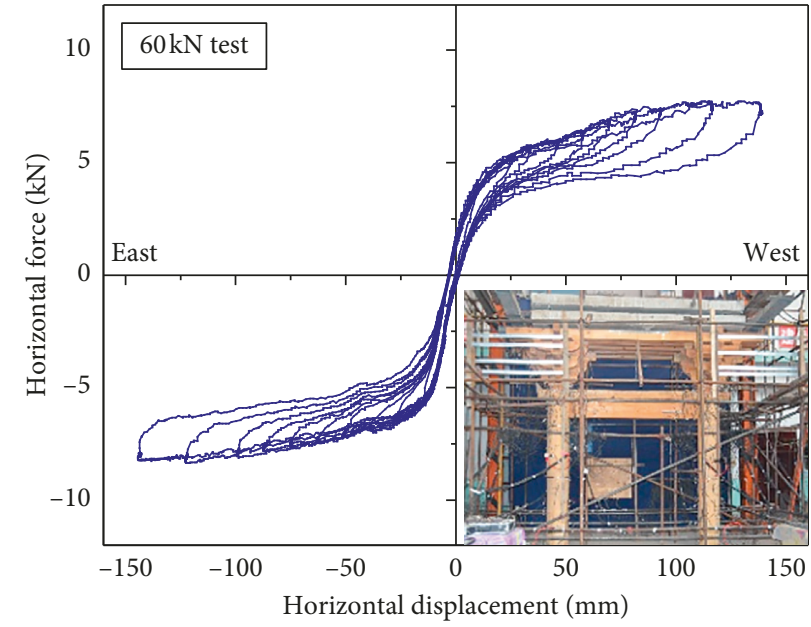

(b)

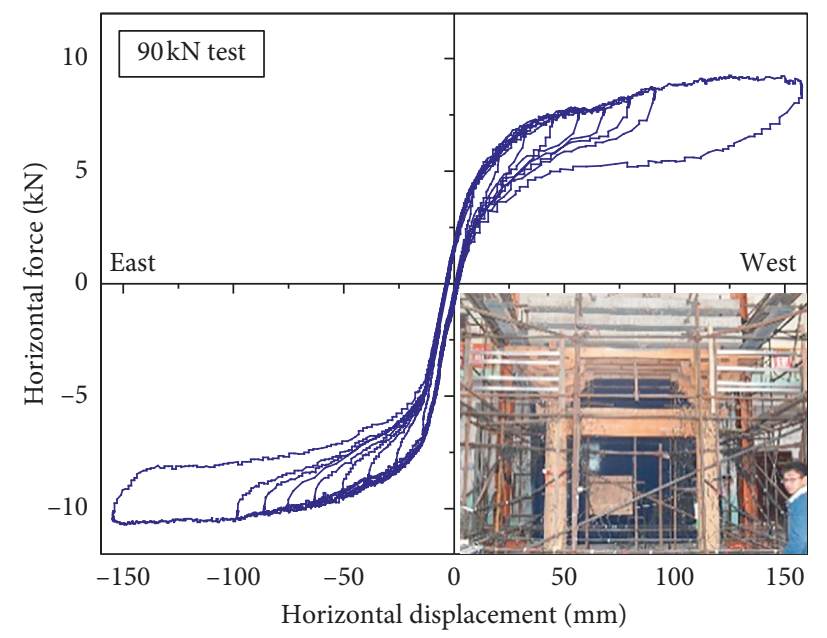

(c)

FiguRE 7: Hysteretic curves under three vertical loading grades. (a) Vertical load: $30 \mathrm{kN}$, (b) vertical load: $60 \mathrm{kN}$, and (c) vertical load: $90 \mathrm{kN}$.

anticlockwise rotation, while rail 1 rotated clockwise, resulting in a gradually developing gap between them (Figure 6(h)). Also, the wooden dowels experienced oblique shear deformation (Figure 6(i)), indicating that there was sliding friction present apart from the different states of rotation of the beam and rail 1.

The bracket sets remained well preserved during the whole horizontal reciprocating loading process, and there was no extension of initial fractures, and no new fractures formed in its components. No sliding was observed between rail 2-2 and the concrete slabs or between the column bottom of the model and the concrete ground. The deformation of the test model was mainly manifested in the form of rotation and plastic deformation of the components of the column framework. Rotation deformation was mainly exhibited via column rocking behavior which resulted in the pullout of the tenons from the mortises. The plastic deformation was mainly exhibited via the compressive deformation of the mortisetenon joints, the bending deformation of the wooden dowels connecting the columns and rail 1 , the compressive deformation between the top of the columns and the bottom of rail 1 , and the shear and bending deformation of the wooden dowels connecting the beam and rail 1 .

The loading phenomena observed on the eastern side were similar to those observed on the western side.

Lastly, it was noted that the test model was not a rigid system with respect to the four-chain structure formed by the steel columns, bar chains, and the test model. Instead, there was a story drift and compressive deformation caused by the vertical loads during horizontal loading. However, since the story drift was less than the horizontal displacement and the vertical compression deformation was also small, the bar chains did remain "horizontal" at all times (average angle $=0.14^{\circ}$ and $0.21^{\circ}$, respectively, for bar chains 1 and 2 ) and thus satisfy the horizontal loading requirements of the test model.

\section{Test Results and Discussion}

5.1. Hysteresis Curves. Hysteresis curves can be plotted using the load-displacement data recorded during the horizontal reciprocating loading experiments carried out on the test 
model (Figure 7). The curves are asymmetrical and exhibit pinching effects. The pinching effect becomes increasingly more significant as the horizontal control displacement and vertical load increase.

Initially, as load is applied to the model, the slope is larger implying a larger stiffness. This part of the curve is approximately linear and indicates that the test model behaves elastically. The slope of the curve declines significantly as the horizontal displacement increases, meaning a great degradation in stiffness. As the horizontal displacement continues to increase, the decreasing rate of the slope slows down, suggesting that the stiffness degradation also slows down. The various horizontal control displacements used produce similar loading path curves.

During the initial unloading stage, larger slope on the load-displacement curve and obvious hysteresis are noted, increasing the hysteretic energy dissipation. With decreasing horizontal displacements, the difference in the slopes on the loading and unloading curves increases first and then decreases. This implies that the components are exhibiting new dissipation energies. This phase reflects the maximum energy dissipation and more significant positive hysteresis. As the horizontal displacement further decreases, the slope increases significantly, thus increasing the stiffness greatly. As in the loading curve, a region of sudden change also appears in the unloading curve. During the final phase of the unloading process, the curve shows an approximately linear relationship and tends to return to the starting position. Although the residual deformation increases with an increasing vertical load, the total residual deformation is deemed quite small, indicating that the full-scale model has a significant capacity of self-restoring. Apparent different paths of the unloading curves under a wide range of control displacements are observed, suggesting that hysteretic energy dissipation in the test model mainly occurs in the unloading phase.

5.2. Skeleton Curves. Skeleton curves as generated from the data are also asymmetrical (Figure 8(a)). In the initial loading phase, the timber structure behaves elastically, and its stiffness is at a maximum. The stiffness degrades rapidly at first when the horizontal displacement exceeds the elastic value, and the degradation then becomes more slow. This represents the elastic-plastic rise stage. As the horizontal displacement continues to rise, the horizontal force in the skeleton curve changes slightly. At this time, the timber structure enters into a "plateau" phase.

According to the above analysis, the skeleton curve can be divided into three linear models: elastic, elastic-plastic rise, and plateau phases. As in Figure $8(\mathrm{~b}), \Delta_{\mathrm{e}}$ and $F_{\mathrm{e}}$ are used to denote the maximum horizontal displacement and force in the elastic phase, respectively, and $\Delta_{\mathrm{p}}$ and $F_{\mathrm{p}}$ are the counterparts in the elastic-plastic rise phase. Moreover, $K_{\mathrm{e}}$ and $K_{\mathrm{p}}$ represent the stiffness in the elastic and elastic-plastic rise phases, respectively. Averaging the test results from the positive and reverse loadings, the relationships between the parameters in the model and the vertical loads used can be derived, as shown in Tables 3 and 4. Discussion for each phase is given in the following sections.

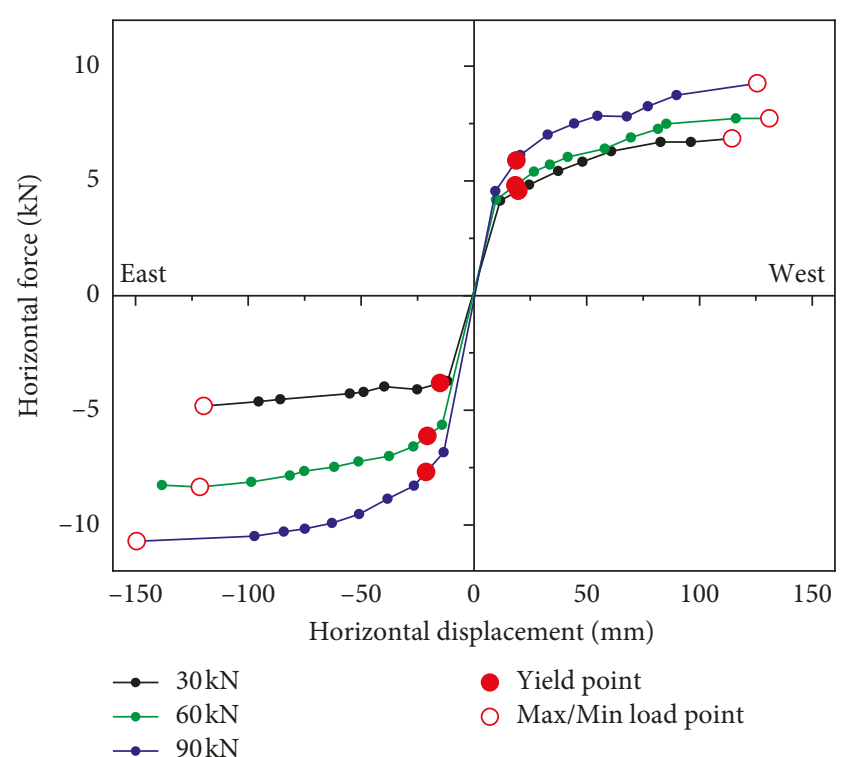

(a)

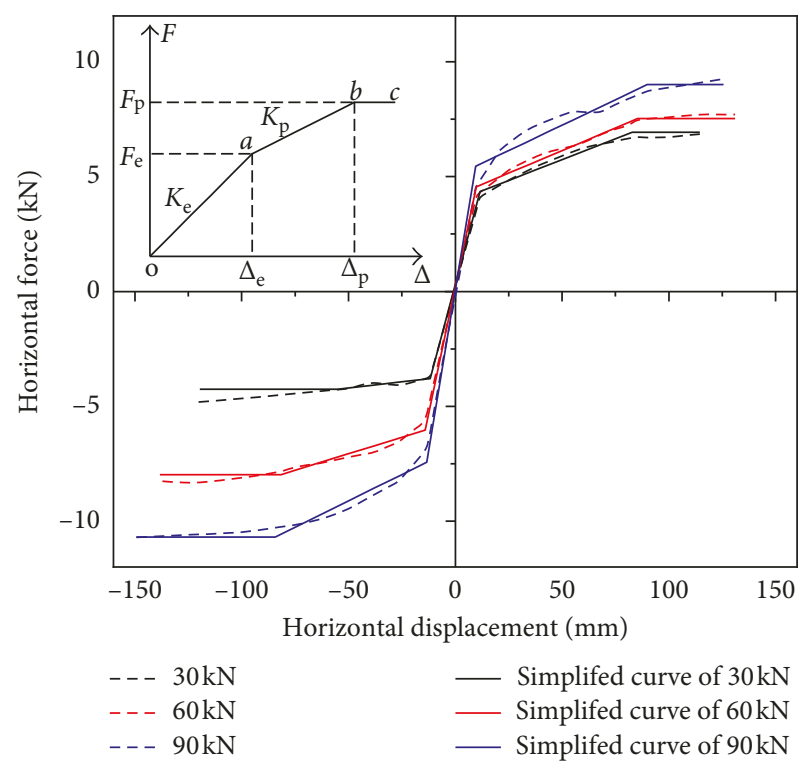

(b)

FigURE 8: Skeleton curves and simplified curve with critical points. (a) Skeleton curves; (b) three-phase linear model.

5.2.1. Elastic Phase (oa). The vertical load exerts an insignificant effect in the elastic range, whose average lies between $-11.7 \mathrm{~mm}$ and $11.7 \mathrm{~mm}$. An increase in the vertical load improves the horizontal lateral force and elastic stiffness of the timber structure. The elastic stiffness increases with the vertical load in an approximately linear fashion. Also, the rate of growth in the elastic stiffness under the third level vertical load is about $4 \%$ lower than that under the second level vertical load.

5.2.2. Elastic-Plastic Rise Phase (ab). An increase in the vertical load improves the lateral horizontal force, yield load, and yield inclination [27] and so extends the elasticplastic rise phase. The stiffness of the structure under the 
TABLE 3: The basic parameters of the three-phase linear model.

\begin{tabular}{|c|c|c|c|c|c|c|c|c|c|c|}
\hline \multirow[t]{2}{*}{$N(\mathrm{kN})$} & \multicolumn{2}{|c|}{ Elastic phase } & \multicolumn{3}{|c|}{ Yield point } & \multicolumn{2}{|c|}{$\begin{array}{c}\text { Elastic-plastic rise } \\
\text { phase }\end{array}$} & \multicolumn{3}{|c|}{ Plateau phase } \\
\hline & $\Delta_{\mathrm{e}}(\mathrm{mm})$ & $F_{\mathrm{e}}(\mathrm{kN})$ & $\Delta_{\mathrm{y}}(\mathrm{mm})$ & $F_{\mathrm{y}}(\mathrm{kN})$ & $\theta_{\mathrm{y}}(\mathrm{rad})$ & $\Delta_{\mathrm{p}}(\mathrm{mm})$ & $F_{\mathrm{p}}(\mathrm{kN})$ & $\Delta_{\max }(\mathrm{mm})$ & $F_{\max }(\mathrm{kN})$ & $\theta_{\max }(\mathrm{rad})$ \\
\hline 30 (1st load) & 11.674 & 3.930 & 17.330 & 4.194 & $1 / 193$ & 68.871 & 5.488 & 118.962 & 5.833 & $1 / 28$ \\
\hline 60 (2nd load) & 11.946 & 4.907 & 19.559 & 5.464 & $1 / 171$ & 83.396 & 7.668 & 141.769 & 8.033 & $1 / 24$ \\
\hline \multirow[t]{5}{*}{90 (3rd load) } & 11.403 & 5.696 & 19.986 & 6.788 & $1 / 167$ & 87.061 & 9.512 & 156.248 & 9.983 & $1 / 21$ \\
\hline & \multicolumn{10}{|c|}{$F_{\mathrm{e}}=-0.0001 N^{2}+0.0419 N+2.765 \quad\left(R^{2}=1\right)$} \\
\hline & \multicolumn{10}{|c|}{$F_{\mathrm{y}}=0.0432 N+2.888 \quad\left(R^{2}=0.9999\right)$} \\
\hline & \multicolumn{10}{|c|}{$\Delta_{\mathrm{p}}=-0.006 N^{2}+1.0272 N+43.486 \quad\left(R^{2}=1\right)$} \\
\hline & \multicolumn{10}{|c|}{$F_{\mathrm{p}}=-0.0002 N^{2}+0.0895 N+2.972 \quad\left(R^{2}=1\right)$} \\
\hline
\end{tabular}

Note. $\Delta_{\mathrm{e}}$ and $F_{\mathrm{e}}=\max$ displacement and max force in the elastic phase, respectively; $F_{\mathrm{y}}, \Delta_{\mathrm{y}}$, and $\theta_{\mathrm{y}}=$ force, displacement, and incidence at the yield point, respectively; $\Delta_{\mathrm{p}}$ and $F_{\mathrm{p}}=\max$ displacement and max force in the elastic-plastic rise phase, respectively; $F_{\max }, \Delta_{\max }$, and $\theta_{\max }=$ ultimate horizontal load, max horizontal displacement, and max incidence, respectively.

TABLE 4: The characteristic parameters of the three-phase linear model.

\begin{tabular}{|c|c|c|c|c|c|c|c|}
\hline \multirow{2}{*}{$N(\mathrm{kN})$} & \multicolumn{2}{|c|}{ Elastic phase } & \multirow{2}{*}{$\begin{array}{l}\text { Yield point } \\
\qquad K_{\mathrm{y}}\end{array}$} & \multicolumn{2}{|c|}{$\begin{array}{c}\text { Elastic-plastic rise } \\
\text { phase }\end{array}$} & \multicolumn{2}{|c|}{ Characteristic values } \\
\hline & $K_{\mathrm{e}}$ & $\rho_{K_{\mathrm{e}}}(\%)$ & & $K_{\mathrm{p}}$ & $\rho_{K_{\mathrm{p}}}(\%)$ & $F_{\max } / F_{\mathrm{y}}$ & $\Delta_{\max } / \Delta_{\mathrm{y}}$ \\
\hline 30 (1st load) & 0.337 & - & 0.242 & 0.027 & - & 1.391 & 6.865 \\
\hline 60 (2nd load) & 0.411 & 22.025 & 0.279 & 0.039 & 41.843 & 1.470 & 7.248 \\
\hline \multirow[t]{4}{*}{90 (3rd load) } & 0.500 & 21.614 & 0.340 & 0.050 & 30.501 & 1.471 & 7.818 \\
\hline & \multicolumn{7}{|c|}{$K_{\mathrm{e}}=0.0027 N+0.2527 \quad\left(R^{2}=0.9973\right)$} \\
\hline & \multicolumn{7}{|c|}{$K_{\mathrm{y}}=1 \times 10^{-5} N^{2}+1 \times 10^{-4} N+0.2276 \quad\left(R^{2}=1\right)$} \\
\hline & \multicolumn{7}{|c|}{$K_{\mathrm{p}}=0.0004 N+0.0156 \quad\left(R^{2}=0.9999\right)$} \\
\hline
\end{tabular}

Note. $K_{\mathrm{e}}$ and $K_{\mathrm{p}}=$ the stiffness in elastic and elastic-plastic rise phases, respectively, and $K_{\mathrm{y}}=$ yield stiffness, where $K_{\mathrm{e}}=F_{\mathrm{e}} / \Delta_{\mathrm{e}}, K_{\mathrm{y}}=F_{\mathrm{y}} / \Delta_{\mathrm{y}}$, and $K_{\mathrm{p}}=\left(F_{\mathrm{p}}-F_{\mathrm{e}}\right) /\left(\Delta_{\mathrm{p}}-\Delta_{\mathrm{e}}\right) ; \rho_{K_{\mathrm{e}}}, \rho_{K_{\mathrm{y}}}$, and $\rho_{K_{\mathrm{p}}}=$ the change rates of stiffness in the elastic phase, at the yield point, and in the elastic-plastic rise phase, respectively, where $\rho_{\mathrm{K}}=\left(K_{\mathrm{B}}-K_{\mathrm{A}}\right) \times 100 / K_{\mathrm{A}}\left(K_{\mathrm{A}}\right.$ refers to the stiffness of $K_{\mathrm{B}}$ under the higher level of vertical loads).

third level vertical load is about $11 \%$ lower than that under the second level load, and the rate of growth of the stiffness declines. The vertical load exerts an insignificant effect on the yield displacement. Moreover, the stiffness and yield load both grow approximately linearly with the vertical load.

5.2.3. Flat Phase $(b c)$. The maximum inclination of the timber structure ranges from $1 / 28$ to $1 / 21$. Such values are larger than the ultimate inclination $(1 / 30)$ specified in the Technical Code for Maintenance and Strengthening of Ancient Timber Buildings in China [28]. In addition, the maximum displacement is about 7.3 times the yield displacement. However, no obvious damage was observed in the full-scale model during the tests, indicating that the timber structure has a favorable plastic deformation capacity and good ductility.

As the three-phase linear model is just an approximate model, the ultimate load is hence slightly larger than the maximum lateral horizontal force in the elastic-plastic phase. As the vertical load increases, the ultimate load (about 1.4 times the yield load), maximum displacement, and maximum inclination all rise. This shows that increasing the vertical load improves the ultimate bearing and deformation capacities of the timber structure and delays the onset of damage to the structure. This further indicates that a heavy roof up to a certain degree is more favorable to the structure.

5.3. Energy-Dissipation Capacity. The energy-dissipation capacity of a structure is generally specified by quantifying the hysteretic energy dissipation ( $E$-hy) or the equivalent viscous damping coefficient $\left(h_{\mathrm{e}}\right)$. The former corresponds to the area enclosed by a hysteretic loop, while the $h_{\mathrm{e}}$ coefficient corresponds to the ratio of $E$-hy to the elastic energy under the same peak load. The two measures can be obtained for the three levels of vertical load according to (1) and Figure 9(a) [29]. It can be seen from Figures 9(b) and 9(c) that

$$
h_{\mathrm{e}}=\frac{1}{2 \pi} \frac{S_{\mathrm{abc}}+S_{\mathrm{cda}}}{S_{\mathrm{obe}}+S_{\mathrm{odf}}}
$$

where $h_{\mathrm{e}}$ is the equivalent viscous damping coefficient, $S_{\mathrm{abc}}$ and $S_{\mathrm{cda}}$ are, respectively, the areas enclosed by curves abc and cda, and $S_{\text {obe }}$ and $S_{\text {odf }}$ are, respectively, the areas of triangles obe and odf.

(1) E-hy increases nonlinearly with increasing horizontal displacements. Increasing the vertical load enhances the $E$-hy of the timber structure, and the amplitude of the increase does not increase monotonically with increasing horizontal displacements. The E-hy value of the structure under the second 


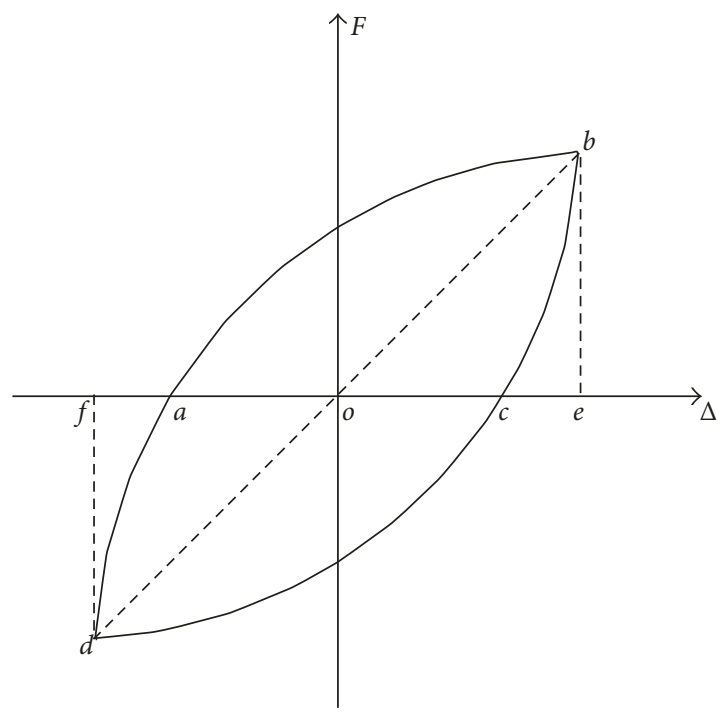

(a)

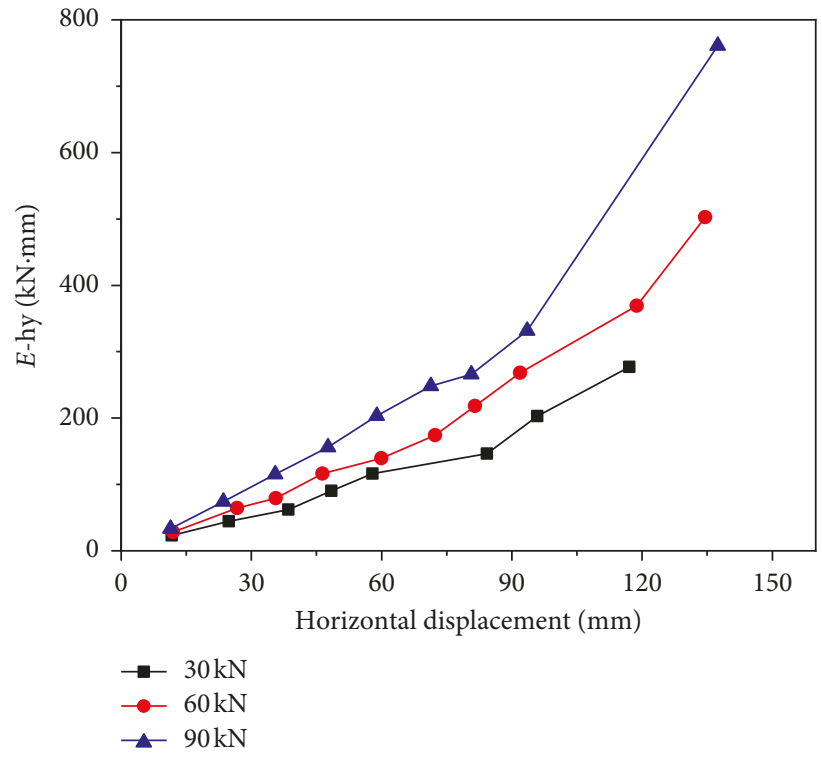

(b)

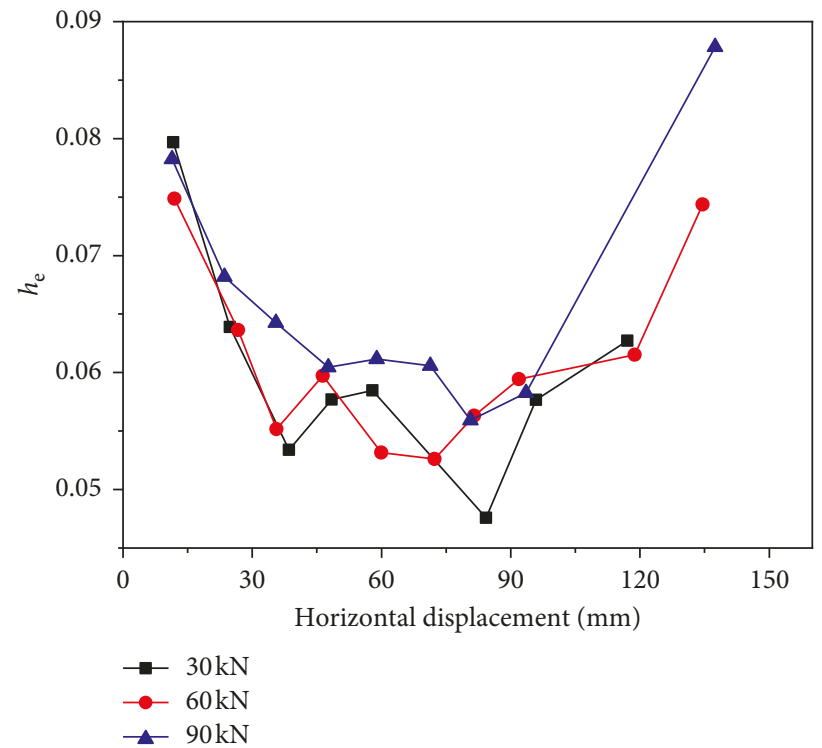

(c)

Figure 9: Curves of the energy dissipation. (a) Lateral force-displacement hysteretic loop; (b) curves of the hysteretic energy dissipation (E-hy); (c) curves of the equivalent viscous damping coefficient $\left(h_{\mathrm{e}}\right)$.

level of vertical load is 1.18-1.58 times that under the first level. On the other hand, the $E$-hy value under the third level of vertical load is $1.20-1.48$ times that under the second level.

(2) As the horizontal displacement increases, the changes occurring in the $h_{\mathrm{e}}$ value can be split into four stages: rapid decrease, slight rise, slight decrease, and rapid increase (overall trend: one decreases first followed by a rise). As the vertical load increases, $h_{\mathrm{e}}$ increases generally. The ratio of $h_{\mathrm{e}}$ under the second level vertical load to that under the first level is 0.92-1.2. Meanwhile, the ratio of $h_{\mathrm{e}}$ under the third level vertical load to that under the second level is 0.99-1.15.
5.4. Stiffness Changes. When analyzing seismic responses, the tangent stiffness of a structure is frequently replaced with the secant stiffness. By carrying out the calculation shown in (2) [30], curves showing the degradation of the stiffness and the degradation rate of the timber structure can be obtained (Figure 10):

$$
K_{j}=\frac{\left|+F_{j}\right|+\left|-F_{j}\right|}{\left|+\Delta_{j}\right|+\left|-\Delta_{j}\right|},
$$

where $j$ is the sequence number of the loading cycle, $F_{j}$ is the peak load of the cycle, and $\Delta_{j}$ is the displacement corresponding to $F_{j}$. 


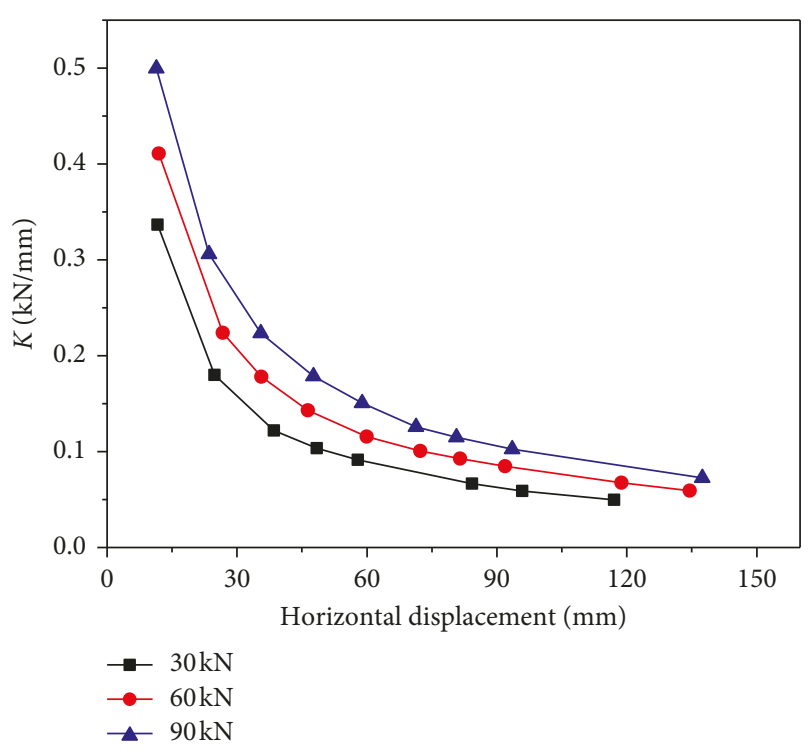

(a)

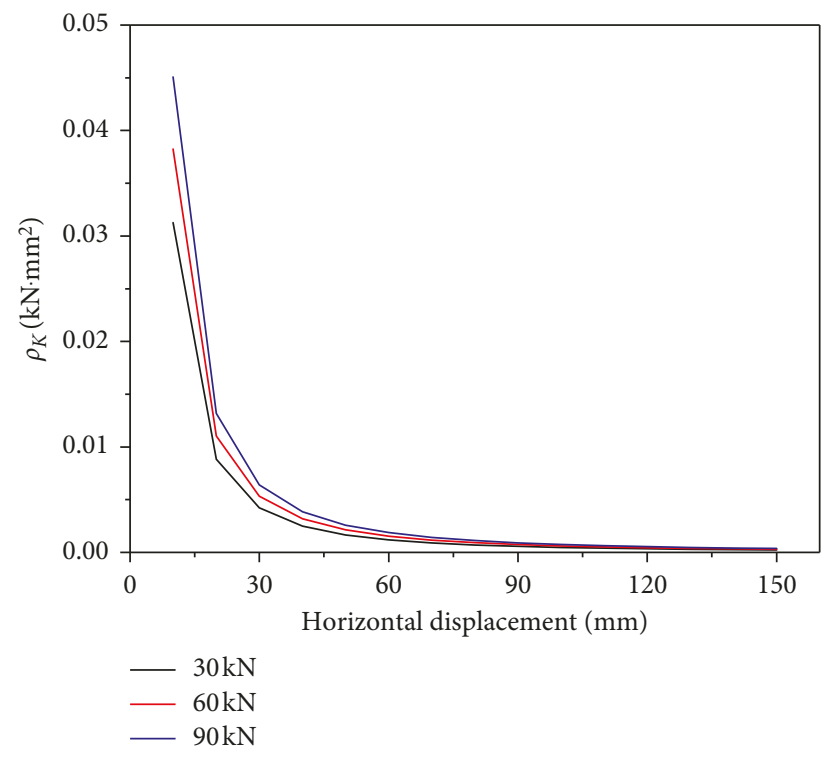

(b)

Figure 10: Stiffness change curves. (a) Stiffness degradation curves; (b) stiffness degradation rate curves.

The stiffness of the timber structure degrades rapidly at first with an increasing horizontal displacement and then degrades more slowly. Increasing the vertical load improves the stiffness of the timber structure, and the amplitude of the increase gradually declines as the horizontal displacement increases. This indicates that an increase in horizontal displacement weakens the effect of the vertical load on stiffness. The amplitude of increase of the stiffness under the second level vertical load is $6.49-11.11 \%$ larger than that under the third level vertical load. This means that the increase in the amplitude of the stiffness decreases as the vertical load increases for a given horizontal displacement.

The stiffness rapidly degrades before the horizontal displacement reaches approximately $80 \mathrm{~mm}$ (in the elastic-plastic rise phase). The rate of stiffness degradation grows with increasing vertical loads. When the horizontal displacement is greater than approximately $80 \mathrm{~mm}$ (in the plateau phase), the rate of stiffness degradation stabilizes, and the vertical load essentially has no effect on the degradation rate.

\section{Conclusions}

The horizontal low-cycle and reciprocating loading tests were conducted on a full-scale single-span model of a traditional Chinese timber structure considering different vertical loads. By studying the hysteretic behavior observed, the following primary findings are offered:

(1) The bar chains employed in the tests remain horizontal at all times. Thus, the synchronous loading technique used satisfies the necessary requirement of maintaining the horizontal loading for the rotating structure and also serves a protective role.

(2) The timber structure has a significant capacity of selfrestoring and deformation. The deformations consist mainly of the pullout of the tenons from the mortises and the plastic deformation caused by the bending, compression, and shear among the different components in the column framework. The hysteretic energy dissipation displays mainly in the unloading phase, and the hysteresis in displacements occurs in the initial unloading stage which increases the hysteretic energy dissipation. Pinching effects become increasingly more significant as the horizontal displacement and vertical load increase.

(3) The lateral horizontal force and hysteretic dissipation energy in the timber structure increase with horizontal displacements. The equivalent viscous damping coefficient decreases first and then increases. The stiffness degrades rapidly at first, followed by a slower degradation.

(4) Increasing the vertical load improves the lateral horizontal force, stiffness, deformation, and energydissipating capacity of the timber structure and extends the elastic-plastic range. However, an increase in horizontal displacements decreases the effect of vertical load on stiffness. In addition, the rate of degradation of the stiffness increases with increasing vertical loads if the horizontal displacement is small. On the other hand, if the horizontal displacement is large, the vertical load has an insignificant effect on the rate of degradation of the stiffness.

\section{Conflicts of Interest}

The authors declare that they have no conflicts of interest.

\section{Acknowledgments}

The authors would like to express their gratitude to the Chinese National Natural Science for providing the financial 
support towards this study under Grant nos. 51338001 and 51278324.

\section{References}

[1] S. Y. Yeo, M. F. Hsu, K. Komatsu, Y. L. Chung, and W. S. Chang, "Shaking table test of the Taiwanese traditional Dieh-Dou timber frame," International Journal of Architectural Heritage, vol. 10, no. 5, pp. 539-557, 2016.

[2] Q. Zhou, W. M. Yan, X. S. Yang, and J. B. Ji, "Damage of ancient Chinese architecture caused by the Wenchuan earthquake," Sciences of Conservation and Archaeology, vol. 22, no. 1, pp. 37-45, 2010.

[3] J. Wang, J. He, N. Yang, and Q. Yang, "Study on aseismic characteristics of Tibetan ancient timber structure," Advances in Materials Science and Engineering, vol. 2017, Article ID 8186768, 15 pages, 2017.

[4] A. Harrer, Fan-Shaped Bracket Sets and Their Application in Religious Timber Architecture of Shanxi Province, Ph.D. dissertation, University of Pennsylvania, Philadelphia, PA, USA, 2010.

[5] I. Tsuwa, M. Koshihara, K. Fujita, and I. Sakamoto, "A study on the size effect of bracket complexes used in traditional timber structures on the vibration characteristics," in Proceedings of the 10th World Conference on Timber Engineering, pp. 1344-1351, Miyazaki, Japan, 2008.

[6] Y. Sui, H. T. Zhao, J. Y. Xue, and X. C. Zhang, "Experimental study on stiffness of Dougong in Chinese ancient buildings," Advanced Materials Research, vol. 368-373, pp. 819-822, 2012.

[7] K. Fujita, I. Sakamoto, Y. Ohashi, and M. Kimura, "Static and dynamic loading tests of bracket complexes used in traditional timber structures in Japan," in Proceedings of the 12th World Conference on Earthquake Engineering, pp. 851-858, Auckland, New Zealand, 2000.

[8] S. Y. Yeo, K. Komatsu, M. F. Hsu, and Z. Que, "Mechanical model for complex brackets system of the Taiwanese traditional Dieh-Dou timber structures," Advances in Structural Engineering, vol. 19, no. 1, pp. 65-85, 2016.

[9] Y. Sui, H. T. Zhao, J. Y. Xue, H. Y. Zhang, and Q. F. Xie, "Experimental study on characteristics of mortise-tenon joints in historic timber buildings," World Earthquake Engineering, vol. 26, no. 2, pp. 88-92, 2010.

[10] Q. Chun, Z. Yue, and J. Pan, "Experimental study on seismic characteristics of typical mortise-tenon joints of Chinese southern traditional timber frame buildings," Science China Technological Sciences, vol. 54, no. 9, pp. 2404-2411, 2011.

[11] K. Ogawa, Y. Sasaki, and M. Yamasaki, "Theoretical modeling and experimental study of Japanese "Watari-ago" joints," Journal of Wood Science, vol. 61, pp. 481-491, 2015.

[12] K. Ogawa, Y. Sasaki, and M. Yamasaki, "Theoretical estimation of the mechanical performance of traditional mortise-tenon joint involving a gap," Journal of Wood Science, vol. 62, pp. 242-250, 2016.

[13] S. Šilih, S. Kravanja, and M. Premrov, "Shape and discrete sizing optimization of timber trusses by considering of joint flexibility," Advances in Engineering Software, vol. 41, no. 2, pp. 286-294, 2010.

[14] A. F. Moshtaghin, S. Franke, T. Keller, and A. P. Vassilopoulos, "Experimental characterization of longitudinal mechanical properties of clear timber: random spatial variability and size effects," Construction and Building Materials, vol. 120, pp. 432-441, 2016.

[15] H. Tanahashi and Y. Suzuki, "Elasto-plastic Pasternak model simulation of static and dynamic loading tests of traditional wooden frames," in Proceedings of the 11th World Conference on Timber Engineering, pp. 3309-3318, Riva del Garda, Italy, 2010.

[16] M. Maeno, Y. Suzuki, T. Ohshita, and A. Kitahara, "Seismic response characteristics of traditional wooden frame by fullscale dynamic and static tests," in Proceedings of the 13th World Conference on Earthquake Engineering, pp. 1184-1194, Vancouver, BC, Canada, 2004.

[17] Y. Suzuki and M. Maeno, "Structural mechanism of traditional wooden frames by dynamic and static tests," Structural Control and Health Monitoring, vol. 13, no. 1, pp. 508-522, 2006.

[18] T. Okubo, "Traditional wisdom for disaster mitigation in history of Japanese architectures and historic cities," Journal of Cultural Heritage, vol. 20, pp. 715-724, 2016.

[19] C. Park, H. Kim, C. Eom, G. Kim, and J. Lee, "Effect of lintel on horizontal load-carrying capacity in post-beam structure," Journal of Wood Science, vol. 60, pp. 30-38, 2014.

[20] J. Li, Ying Zao Fa Shi, China Bookstore Press, PR China, 2006.

[21] H. T. Zhao, F. L. Zhang, and J. Y. Xue, "The research of dynamic properties on the roof in ancient timber buildings," Advanced Materials Research, vol. 368-373, pp. 118-123, 2012.

[22] F. L. Zhang, H. T. Zhao, J. Y. Xue, H. Ma, and X. C. Zhang, "The analysis of dynamic properties of the roof-beams system in ancient timber buildings," Engineering Mechanics, vol. 29, no. 8, pp. 184-201, 2012.

[23] GB/T 1928-2009, General Requirements for Physical and Mechanical Tests of Wood, , Chinese Academy of Forestry Sciences, Shenyang, China, 2009.

[24] J. Y. Chen, X. W. Shi, Q. F. Niu, J. W. Wei, T. Y. Li, and Y.X. Zhao, "Analysis of similar CaiFen modular system based on the weight of the roof of Song dynasty," Journal of Civil, Architectural \& Environmental Engineering, vol. 38, pp. 27-33, 2016.

[25] Q. F. Niu, X. W. Shi, J. Y. Chen, J. W. Wei, and T. Y. Li, “A kind of new sensor used in the measurement of large horizontal displacement," Journal of Civil, Architectural \& Environmental Engineering, vol. 38, pp. 59-65, 2016.

[26] X. W. Shi, J. Y. Chen, G. H. Chuan, and T. Y. Li, "Geometric nonlinear analysis of the displacement sensor with a wide measuring range," Journal of Huazhong University of Science and Technology, vol. 45, no. 7, pp. 6-10, 2017.

[27] R. Park, "State of the art report-ductility evaluation from laboratory and analytical testing," in Proceedings of the Ninth World Conference on Earthquake Engineering, vol. 8, pp. 605-616, Tokyo, Japan, 1988.

[28] GB/50165-92, Technical Code for Maintenance and Strengthening of Ancient Timber Buildings, Sichuan Institute of Building Research, PR China, 1993.

[29] F. Vieux-Champagne, Y. Sieffert, S. Grange, A. Polastri, A. Ceccotti, and L. Daudeville, "Experimental analysis of seismic resistance of timber-framed structures with stones and earth infill," Engineering Structures, vol. 69, pp. 102-115, 2014.

[30] H. W. Shenton, D. W. Dinehart, and T. E. Elliott, "Stiffness and energy degradation of wood frame shear wall," Canadian Journal of Civil Engineering, vol. 25, pp. 412-423, 1998. 


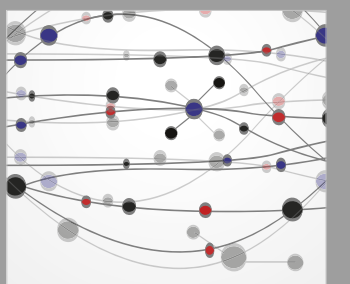

The Scientific World Journal
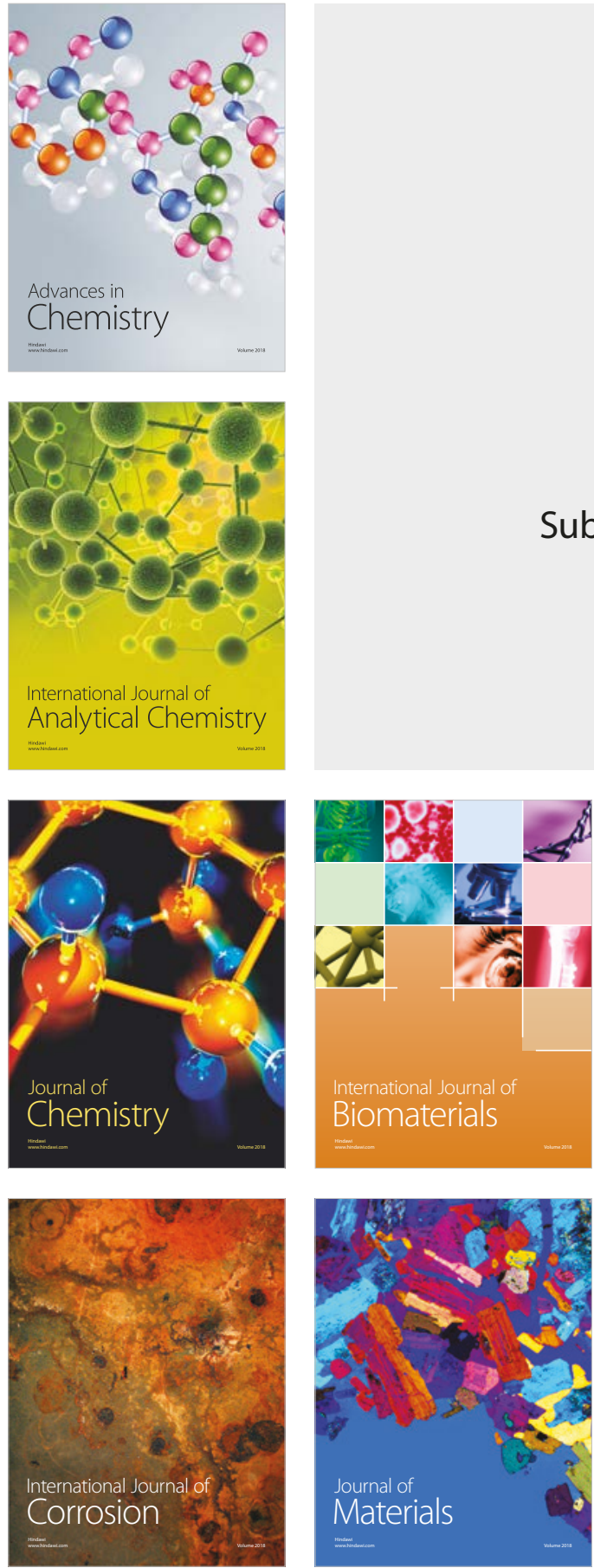

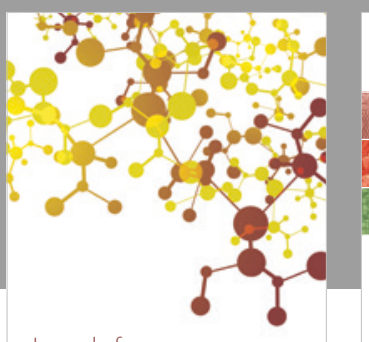

Journal of

Applied Chemistry
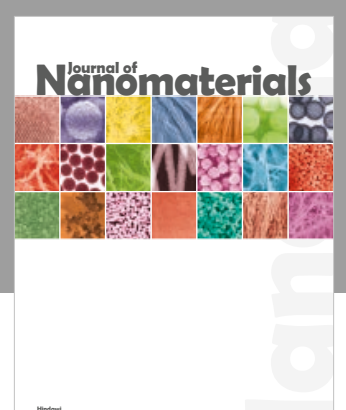

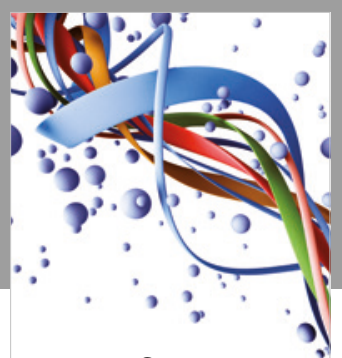

Scientifica

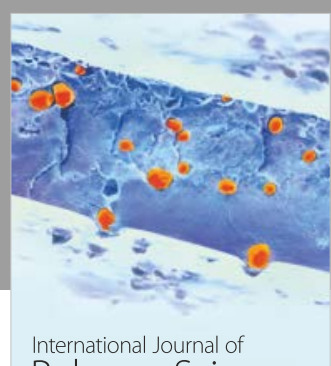

Polymer Science

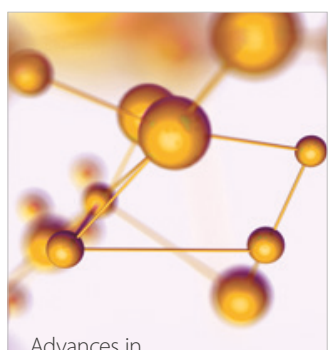

Physical Chemistry
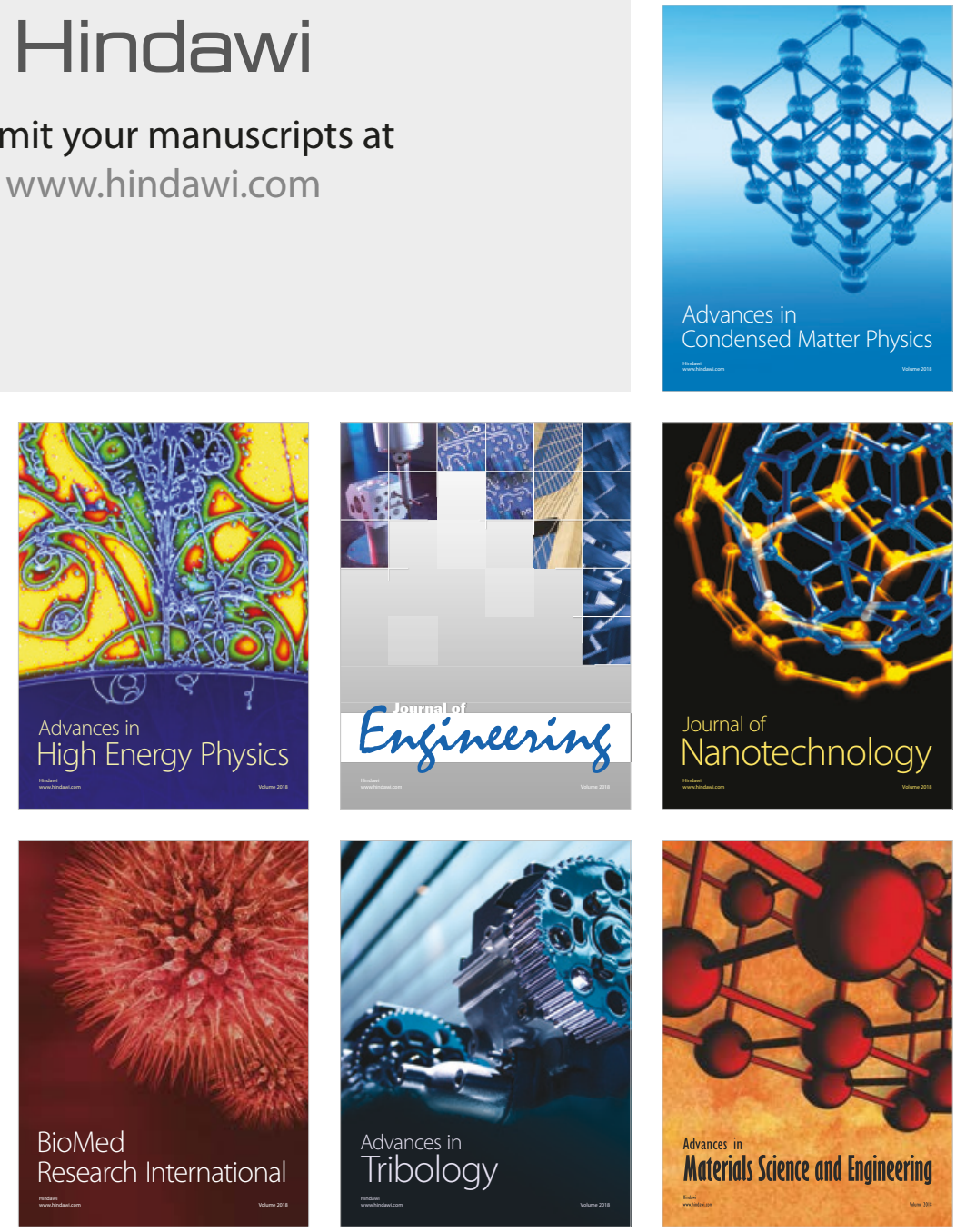